\title{
Research on Cold Core Eddy Change and Phytoplankton Bloom Induced by Typhoons: Case Studies in the South China Sea
}

\author{
Xiao-dong Shang, ${ }^{1}$ Hai-bin $\mathrm{Zhu},{ }^{2}$ Gui-ying Chen, ${ }^{1}$ Chi Xu, ${ }^{1}$ and Qi Yang ${ }^{3}$ \\ ${ }^{1}$ State Key Laboratory of Tropical Oceanography, South China Sea Institute of Oceanology, Chinese Academy of Sciences, \\ Guangzhou 510301, China \\ ${ }^{2}$ Ningxia Meteorological Observatory, Yinchuan 750002, China \\ ${ }^{3}$ Shanghai Marine Observatory, Shanghai 201300, China \\ Correspondence should be addressed to Hai-bin Zhu; zhuhb04@126.com and Gui-ying Chen; gychen@scsio.ac.cn
}

Received 18 December 2014; Revised 13 February 2015; Accepted 28 February 2015

Academic Editor: Shaoqing Zhang

Copyright (C) 2015 Xiao-dong Shang et al. This is an open access article distributed under the Creative Commons Attribution License, which permits unrestricted use, distribution, and reproduction in any medium, provided the original work is properly cited.

\begin{abstract}
The effects of 8 typhoons which passed by coldcore eddy (CCE) areas in the South China Sea (SCS) from 1997 to 2009 were observed and evaluated. The changes in the preexisting CCE acted upon by typhoons were described by eddy kinetic energy (EKE) and eddy available gravitational potential energy (EAGPE). The mechanical energy of CCE was estimated from a two-layer reduced gravity model. Comparing with the scenario that typhoon passes by the region without CCEs, the preexisting CCE area plays an important role in the increase of chlorophyll-a (chl-a) concentration in the CCEs impacted by the typhoons. The preexisting chl-a in CCE is about $25 \% \sim 45 \%$ (8\% 25\%) of postexisting chl-a in CCE for higher (slower) transit speed typhoons. If the EAGPE of CCE increases greatly after typhoon passing by with slow transit speed, so does the chl-a in the CCE area. The EKE (EAGPE) changes of the preexisting CCE are in the order of $\mathrm{O}\left(10^{14} \sim 10^{15} \mathrm{~J}\right)$. EKE and EAGPE of CCE are dominantly enhanced by typhoon with slow transit speed $(<3 \mathrm{~m} / \mathrm{s})$ and the posttyphoon EAGPE is always larger than posttyphoon EKE for 8 cases. The maximum EAGPE change of the preexisting CCE reaches $5.11 \times 10^{15} \mathrm{~J}$, which was induced by typhoon Hagibis.
\end{abstract}

\section{Introduction}

Ocean responses to typhoons have been investigated during the past several decades through theoretical [1], observational [2-4], and numerical methods [5-7]. Typhoons trigger phytoplankton blooms of high chl-a concentration in the ocean. This phenomenon has been previously reported [8-10]. With the development of satellites, more tropical storm-induced phytoplankton blooms in the open oceans $[11,12]$ and in the marginal seas [13], especially in the SCS [14-16], have been studied. The mechanism of phytoplankton blooms is generally supposed to be that typhoon-induced upwelling and vertical mixing bring cold and nutrient or chlorophyllrich water up to the euphotic layer and thus stimulate the biological bloom $[10,11,14]$. Recently, many investigations focus on that phytoplankton blooms are enhanced in a cold core eddy (CCE) when a typhoon passes by $[15,17]$. The preexisting CCE plays a critical role in the development of typhooninduced phytoplankton blooms, and it significantly strengthens the upper ocean dynamics and nutrient responses, which are mainly dependent on two factors $[13,18]$. One is that the cyclonic eddy lifts up the isotherms prior to the arrival of the typhoons, thus leading to lower water temperature and more nutrients than in the case of no eddy at the same depth. The other factor is that typhoons have slow transit speed. Entrainment and upwelling induced by typhoons and upwelling induced by preexisting CCE can inject nutrient water to the euphotic layer and significantly promote biological bloom [19-21].

There has been also considerable research on the sea surface temperature (SST) cooling associated with preexisting mesoscale eddy in response to the passing by of typhoon. For 
example, Zheng et al. [17] investigated that intensive cooling response to typhoon Hai-tang at sea surface is under preexisting cyclonic eddy condition with uplifted thermocline induced by cyclonic flow. By two numerical experiments, Zheng et al. [22] revealed that an accurate representation of the upper dynamic conditions is required to accurately estimate the sea surface cooling by a typhoon. Prasad and Hogan [23] investigated that the variation of regions of extreme cooling depended on the simulated location of the warm core eddy (WCE) by hurricane Ivan. These studies all suggest that preexisting mesoscale eddies play an important role in SST cooling in response to typhoon. The cooling SST with low sea surface height indicates that more cooling water is uplifted by mixing and upwelling induced by cyclonic eddy. When the cooling water brings nutrient water to the upper layer, phytoplankton blooms will occur.

For the preexisting CCE, the SST cooling, sea surface height anomaly (SSHA) changes, and marine phytoplankton blooms impacted by typhoon were investigated (e.g., [13, 17, 22]). However, these rare basic physical parameters, such as SST and SSHA in the sea surface, available by satellite data, can only roughly present some characteristics of CCE. Nowadays, based on SSHA and geostrophic velocities or standard Reynolds averaging procedure [24], the sea surface kinetic energy can be easily estimated. In absence of in situ data, most of the relative studies about eddy kinetic energy (EKE) of CCE focused on sea surface kinetic energy $[25,26]$, which ignore the volume effect of CCE. Meantime, seldom work reported the variations of eddy available gravitational potential energy (EAGPE). Xu et al. [27] postulated a new method to estimate the EKE and EAGPE by a two-layer model including the contribution of an eddy's volume. When typhoons act on CCEs, studying the energy change of preexisting CCEs with volume effect has important implication with the energy transfer between the atmospheric force and the ocean response. Estimating the change of EKE and EAGPE associated with the preexisting CCEs can investigate quantitatively the energy translation from a typhoon to a mesoscale cold eddy and further tell which parameter of a typhoon plays a key role in the change of preexisting CCE's energy. What is the relationship between EAGPE of CCEs and change of chl-a? What plays a key role in the change of chl-a in the CCE area? The answers to these questions can offer observational information for the further study of the interaction between typhoons and CCEs in the physical and biophysical models.

The South China Sea (SCS) is one of the largest marginal seas in the Western Pacific (see Figure 1), and commonly its seasonal thermocline is shallow $(\sim 10 \mathrm{~m})$ in spring and deep $(\sim 80 \mathrm{~m})$ in winter. Meanwhile, the SCS is also a region with frequent typhoons [28] and abundant activity of mesoscale eddies observed all year around [29]. Besides, oligotrophy is a significant characteristic in upper water column of the northern SCS $\left(>20^{\circ} \mathrm{N}\right)$. In winter, due to the fact that the nutrient is relatively rich (the average surface phosphate concentration is $34.6 \mathrm{nmol} / \mathrm{L}$ [30]), the average chl-a concentration of the northern SCS from August 1997 to December 2009 can reach $0.47 \mathrm{mg} / \mathrm{m}^{3}$, while the average chl-a concentration

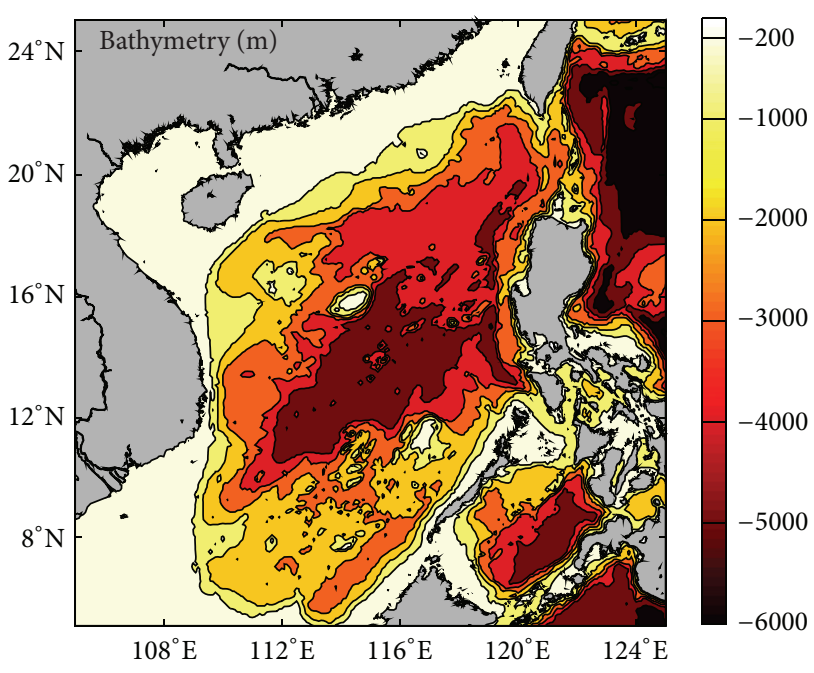

Figure 1: Topographical map of the South China Sea.

of the southern SCS is about $0.17 \mathrm{mg} / \mathrm{m}^{3}$ (see Figure 2). In summer, the average chl-a in the SCS is about $0.1192 \mathrm{mg} / \mathrm{m}^{3}$ because the nutrient is relative oligotrophy (the average surface phosphate concentration in summer is $17.6 \mathrm{nmol} / \mathrm{L}$ [30]). In spring, the average chl-a in the SCS is about $0.1163 \mathrm{mg} / \mathrm{m}^{3}$; therein, the average chl-a in the northern SCS is higher (about $\left.0.22 \mathrm{mg} / \mathrm{m}^{3}\right)$. In autumn, the average chl-a in the SCS is about $0.1492 \mathrm{mg} / \mathrm{m}^{3}$. Both in summer and in autumn, there is a water jet induced by monsoons [31] near the eastern Vietnam coast, where the average chl-a is very high $\left(0.44 \sim 0.47 \mathrm{mg} / \mathrm{m}^{3}\right)$ in autumn and it is relatively weak $\left(0.22 \sim 0.44 \mathrm{mg} / \mathrm{m}^{3}\right)$ in summer. In this paper, we proposed a method to more effectively estimate physical parameters, especially EKE and EAGPE of CCE to reveal the response of the preexisting eddy acted upon by typhoons by using satellite data and a two-layer reduced gravity model. These two parameters are important physical parameters that have a close relation to chl-a change. To avoid regional differences, eight typhoons passed by the preexisting CCE area in the SCS were used to investigate the chl-a change in the CCE area. In addition, when the wind stress of typhoons produced an effect on CCE, the changes in the EKE and EAGPE of CCE before and after the typhoons were calculated to illustrate the energy translation of CCE both on and below the sea surface.

\section{Data and Methods}

2.1. Selection of Cases. The chl-a data were obtained from the Sea-viewing Wide Field-of-view Sensor (SeaWiFS). The level-3 chl-a concentration values taken from the website of National Aeronautics and Space Administration (NASA, http://oceancolor.gsfc.nasa.gov/) were used. These data with $9 \mathrm{~km}$ spatial resolution and 8-day composite were derived from an algorithm called the ocean chlorophyll 4 algorithm (OC4) [32]. Typhoon information, including center location, central pressure, and maximum sustained winds recorded once every six hours, was obtained from the Joint Typhoon Warning Center (JTWC). The average typhoon transit speed 


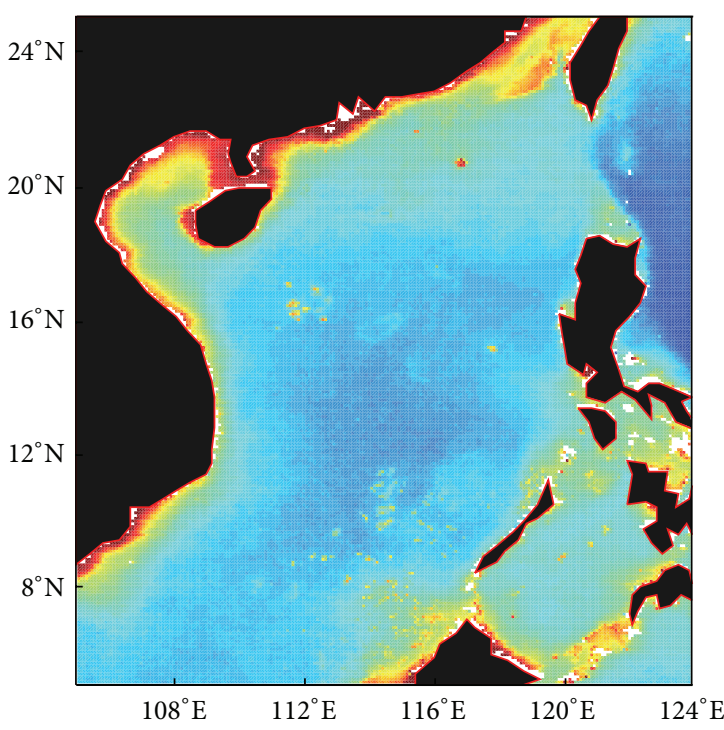

(a) Spring

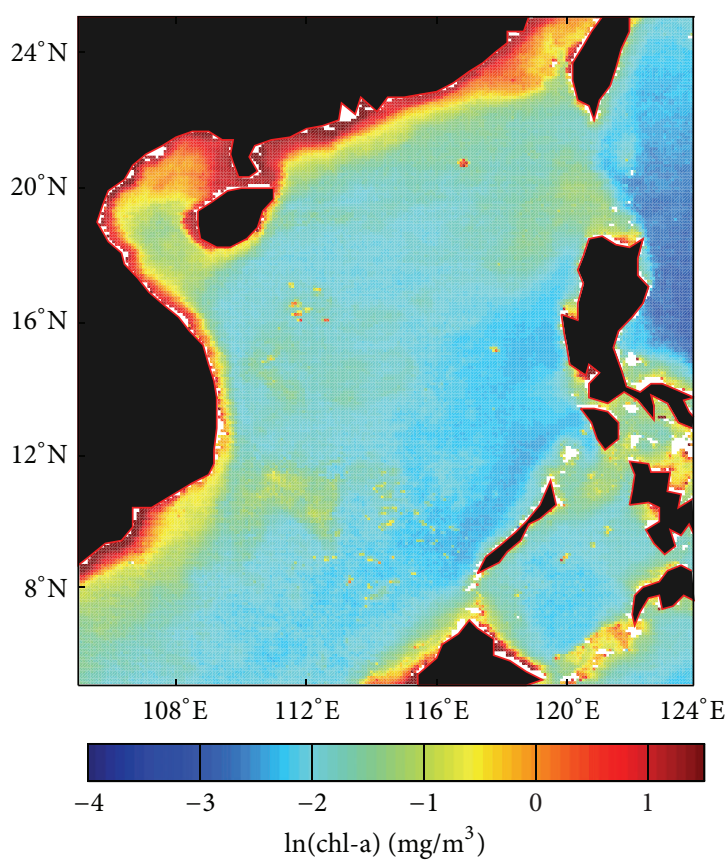

(c) Autumn

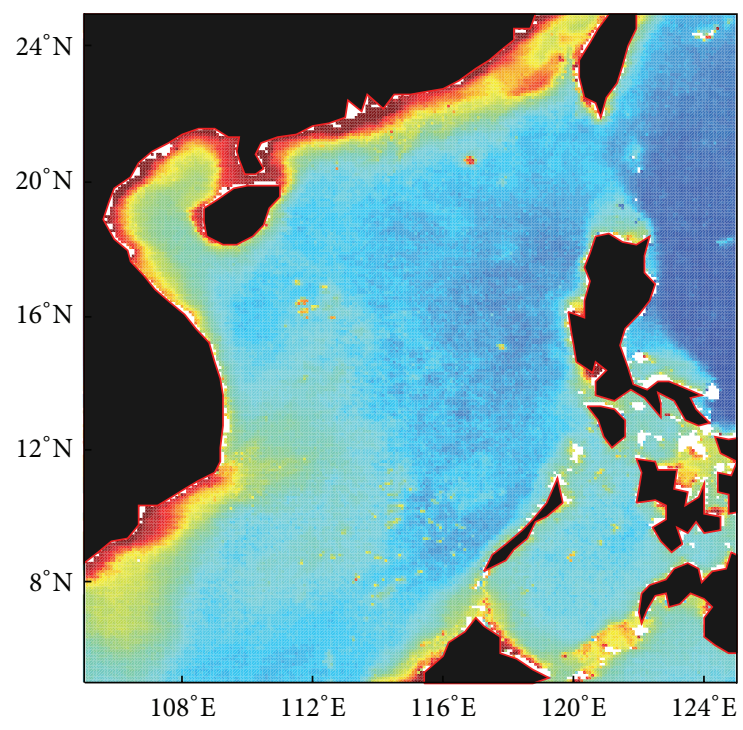

(b) Summer

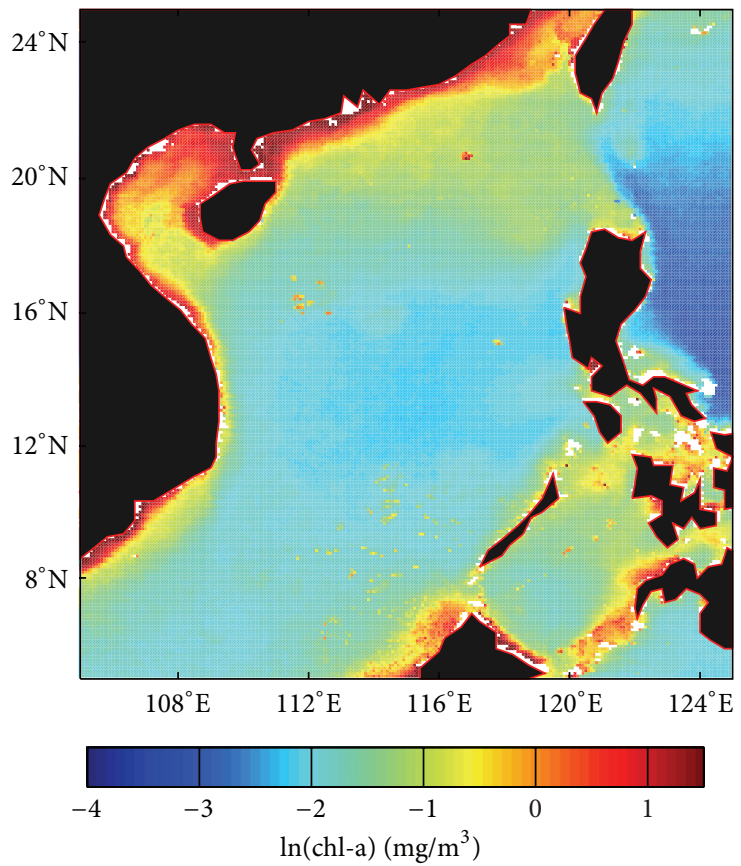

(d) Winter

Figure 2: Seasonal average chl-a concentration from August 1997 to December 2009 in the South China Sea.

and average wind speed when the typhoon center was located within $100 \mathrm{~km}$ of the CCE were estimated. The altimeter data were merged from multisensors including TOPEX and ERS. Data were produced by AVSIO (Archiving, Validation, and Interpretation of Satellite Oceanographic data) with average spatial resolution of $0.3^{\circ}$ and time resolution of 7 days. The daily SST data are from the Remote Sensing Systems TMI (the Tropical Rain Measuring Mission's microwave imager).

To investigate the biological response in the eddy area under the influence of a typhoon, the eligible cases were selected by following these steps. First, the typhoon track records were used to search for the typhoons entering into the SCS. Next the SSHA data were used to check whether the typhoons on the SCS passed by the mesoscale eddy area. Finally, chl-a concentration was calculated in the eddy area where typhoon passed by.

Because 1997 was the first year that the SeaWiFS data were available, this year was chosen as a starting point in our study. The chl-a enhanced by typhoon is mostly attributed to not only the upwelling that brings nutrient water from deep sea to upper layer, but also new phytoplankton growing in the euphotic zone [11]. Thus, the phytoplankton growth to peak concentration needs a delay of several days ( $\sim 5$ days) under the influence of a hurricane $[13,33]$. In fact, the exact number 
of days for chl-a to rise to its peak is still unknown, but it is not the crux of problem. Based on the above considerations, 8 -day, $9 \mathrm{~km}$, and level-3 composite SeaWiFS data were used to satisfy the basic study requirements. Moreover, before and after each typhoon, the SeaWiFS data without a large quantity of cloud cover were used [33], since typhoons are always accompanied by large and intensive cloud, making upper ocean chl-a invisible to the SeaWiFS sensor. In several selected cases, the disturbances of cloud were not able to be precluded. However, compared with the chl-a distribution after typhoon in mesoscale size around the CCE area farthest from the coast, the horizontal gradient of chl-a concentration before typhoon is much smaller. Hence, the data from chla partially covered by cloud can still be used to present chl-a distribution before typhoon. But for chl-a data after typhoon, the chl-a growth rate varies in different regions and its horizontal gradient is large. If the calculated chl-a excluded some other areas covered by cloud, it is a significant error. Therefore, those cases of cloud-free chl-a data in the CCE area were chosen so that the CCE circumscription could be accurately determined.

To identify and track the mesoscale eddy, 3 criteria were followed: (1) there were closed SSHA contours on the SSHA images, and the outermost closed contour of SSHA is the boundary of identified mesoscale eddy; (2) the water depth of the eddy center was deeper than $1000 \mathrm{~m} \mathrm{[34];} \mathrm{(3)} \mathrm{the}$ difference of SSHA values between center maximum and outermost contour, $M$, was more than $6 \mathrm{~cm}$. The accuracy of altimeter data was low near the coast, whereas when the eddy area was located in open ocean, interference with chl-a pixel values from coastal or ocean bottom areas can be avoided. Thus, the second criterion is important. Because the measurement error of the SSHA was around $2 \mathrm{~cm}$, the third criterion was applied.

A mesoscale eddy usually spans several hundred kilometers. A tropical storm with slow transit speed only spends about one day passing through an eddy. According to this, using daily SSHA data to determine the area covered by the eddy is needed, as the weekly SSHA data were not available to distinguish the day that a tropical storm passed through an eddy. The SSHA data of a particular day were obtained by the linear time-interpolation using the two consecutive days of available SSHA data, which were, respectively, before and after this day. The validation of linear time-interpolation was tested by comparing the SSHA data obtained by linear timeinterpolation with AVISO daily SSHA product.

To investigate chl-a variation caused by typhoon, average chl-a concentration in two continuous 8-day periods were calculated (except Utor and Hagibis). The first 8-day data were defined as the "pretyphoon" period which represents the chl-a distribution before typhoon; the second 8-day data were defined as the "posttyphoon" period which represents the chla distribution after typhoon. When the two sets of 8-day data were used, the date of the typhoon passing by the eddy area was chosen to occur at the end of the first 8-day period or at the beginning of the second 8-day period. Because chl-a bloom needs several days after the typhoon passed, the bloom is always present in the second 8-day period. Then the SSHA grid was spatially linearly interpolated into $9 \times 9 \mathrm{~km}$, which

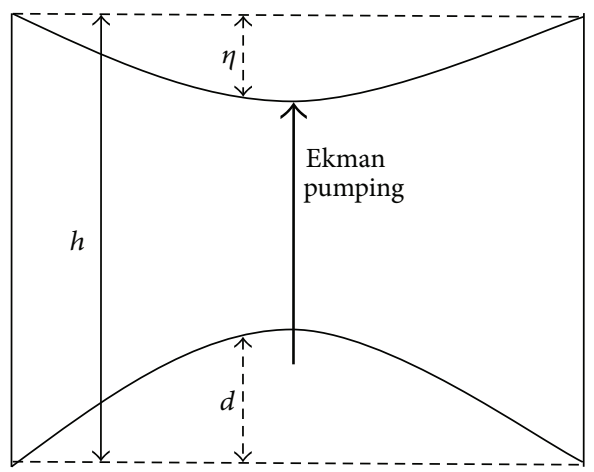

FIGURE 3: The two-layer reduced gravity model.

has the same resolution as the grid of 8-day chl-a data. The chl-a pixel values accumulated when the chl-a pixels were located on the grid points covered by the CCE influenced by typhoon. The average chl-a concentration was derived from the sum of chl-a pixel values divided by the total number of available chl-a pixels on the CCE.

\subsection{CCE's Kinetic Energy and Available Gravitational Potential} Energy's Calculation Methods. The EKE and EAGPE of CCE were calculated by following simplification and assumption. Because we do not have information about eddy's vertical structure and it was reasonable to treat the SSH variability as the vertical displacement signature of the first baroclinic mode [35], a two-layer model (Figure 3) was used to simulate the baroclinic structure of eddies. To specify the depth of interface and the density difference between two layers, a common approach that sets the main pycnocline (thermocline) as the interface of a two-layer model was used. Thus the internal displacement can be linked to the free surface elevation anomaly observed from satellite data to incorporate the vertical structure of eddies. By forming such a firstmode-baroclinic eddy and defining the reference state as the state when there is no surface elevation caused by eddy, both EKE and EAGPE for each eddy can be derived. Here EAGPE means the difference in gravitational potential energy between the reference state and the state where there was an eddy. The two dates of weekly SSHA used to calculate energy were the days before and after the typhoon passed by the eddy area.

In a simple reduced gravity model (Figure 3 ), the relationship between sea surface height anomaly $\eta$ and displacement of thermocline $d$ is

$$
d=\frac{g \eta}{g^{\prime}},
$$

where $g$ is gravitational acceleration and $g^{\prime}$ is reduced gravitational acceleration. $g^{\prime}$ is treated as a constant, that is, $0.03 \mathrm{~m} / \mathrm{s}^{2}$. In the calculation, it is assumed that water density does not change with pressure and the density difference $\Delta \rho$ exists between upper and lower layer. $\Delta \rho$ is obtained from $\Delta \rho=\rho\left(g^{\prime} / g\right)$. Hence upper layer density is $\rho-\Delta \rho$ and lower layer density is $\rho$ (a nominal value of $1020 \mathrm{~kg} / \mathrm{m}^{3}$ used), and $h$ is the upper layer thickness in reduced gravity model. 
TABLE 1: Typhoon information and the spatial average chl-a concentration before and after typhoon overlaid on CCE.

\begin{tabular}{|c|c|c|c|c|c|}
\hline Typhoon's name & $\begin{array}{c}\text { Transit speed } \\
(\mathrm{m} / \mathrm{s})\end{array}$ & $\begin{array}{l}\text { Average wind } \\
\text { speed }(\mathrm{m} / \mathrm{s})\end{array}$ & $\begin{array}{c}\text { Minimum sea } \\
\text { level pressure }(\mathrm{mb})\end{array}$ & $\begin{array}{c}\text { Prestorm } \\
\mathrm{chl}-\mathrm{a}\left(\mathrm{mg} / \mathrm{m}^{3}\right)\end{array}$ & $\begin{array}{c}\text { Poststorm } \\
\text { chl-a }\left(\mathrm{mg} / \mathrm{m}^{3}\right)\end{array}$ \\
\hline Leo & 2.8864 & 49.901 & - & 0.1089 & 0.7174 \\
\hline Lingling & 3.6846 & 55.487 & 927 & 0.1218 & 0.4750 \\
\hline Nanmadol & 6.4741 & 40.127 & 967 & 0.1483 & 0.4323 \\
\hline Kai-tak & 2.1016 & 29.581 & 963 & 0.1661 & 0.8212 \\
\hline Chanchu & 2.7270 & 59.676 & 927 & 0.0847 & 0.3335 \\
\hline Durian & 3.7176 & 44.156 & 954 & 0.1141 & 0.2664 \\
\hline Utor & 4.8184 & 41.156 & 954 & 0.1141 & 0.2454 \\
\hline Hagibis & 1.9072 & 31.438 & 982 & 0.1145 & 1.4338 \\
\hline
\end{tabular}

The current velocities are deduced from weekly SSHA data by using the geostrophic approximation. Meridional and zonal geostrophic velocities are $u_{g}$ and $v_{g}$, respectively:

$$
\begin{aligned}
& u_{g}=-\left(\frac{g}{f}\right) \frac{\partial \eta}{\partial y} \\
& v_{g}=\left(\frac{g}{f}\right) \frac{\partial \eta}{\partial x}
\end{aligned}
$$

where $f$ is the Coriolis parameter. The central difference method was used to calculate horizontal gradient of SSHA, and the number of the grids surrounded by closed outermost contour is $n$ in the eddy area. Average kinetic energy per unit mass is given by

$$
\langle\mathrm{EKE}\rangle_{m}=\sum_{1}^{n} \frac{\left[\left(u_{g, i}^{2}+v_{g, i}^{2}\right) / 2\right]}{n} .
$$

If the area of each grid is $A_{i}$, the kinetic energy of a CCE, including the contribution from the layer thickness and the eddy volume, can be expressed as

$$
\mathrm{EKE}=\sum_{1}^{n}\left[\frac{\left(u_{g, i}^{2}+v_{g, i}^{2}\right)}{2}\right](\rho-\Delta \rho) A_{i}\left(h_{i}-d\right),
$$

where the only parameter that is not known is $h_{i}$. The monthly mean ocean temperature of World Ocean Atlas 2005 (WOA05) provided by National Oceanographic Data Center (NODC) was used to estimate the upper layer thickness. Horizontal resolution of the data is one degree, and temperature values are indicated on 24 layers from 0 to 1500 meters. This dataset is suitable to describe the sea water stratification before the influence of typhoon because the annual and seasonal cycles dominate the variability of the SCS, and the monthly mean climatology is useful to eliminate the effects of upper-layer deepening caused by the typhoon in the calculations of eddy energy. Wind stress energy input to the surface ageostrophic current will be much more significant than that under the circumstance without typhoon so that the upper layer depth will change significantly from pre- to posttyphoons [36], but such an effect is not part of mesoscale eddy-typhoon interaction. Besides, in situ measurements in
TABLE 2: EKE and EAGPE of CCE before and after typhoons.

\begin{tabular}{lcccc}
\hline $\begin{array}{l}\text { Typhoon's } \\
\text { name }\end{array}$ & $\begin{array}{c}\text { Prestorm } \\
\text { EKE }(\mathrm{J})\end{array}$ & $\begin{array}{c}\text { Poststorm } \\
\text { EKE }(\mathrm{J})\end{array}$ & $\begin{array}{c}\text { Prestorm } \\
\text { EAGPE }(\mathrm{J})\end{array}$ & $\begin{array}{c}\text { Poststorm } \\
\text { EAGPE }(\mathrm{J})\end{array}$ \\
\hline Leo & $1.70 E+14$ & $3.70 E+14$ & $1.13 E+15$ & $3.43 E+15$ \\
Lingling & $1.42 E+15$ & $2.42 E+15$ & $2.34 E+15$ & $5.65 E+15$ \\
Nanmadol & $1.45 E+14$ & $1.93 E+14$ & $2.89 E+15$ & $4.53 E+15$ \\
Kai-tak & $2.78 E+14$ & $1.39 E+15$ & $6.50 E+14$ & $2.46 E+15$ \\
Durian & $7.02 E+14$ & $6.85 E+14$ & $1.11 E+15$ & $1.51 E+15$ \\
Utor & $6.85 E+14$ & $1.30 E+15$ & $1.51 E+15$ & $5.17 E+15$ \\
Hagibis & $1.18 E+15$ & $4.06 E+15$ & $6.49 E+14$ & $5.76 E+15$ \\
\hline
\end{tabular}

the South China Sea show that $16^{\circ} \mathrm{C}$ isotherm-depth is appropriate for the upper layer thickness [37]. Thus the depth of $16^{\circ} \mathrm{C}$ isotherm was adopted as the upper-layer thickness $h_{i}$ in present study.

For simplicity, the original position of the sea surface in which there is no perturbation is selected as the reference level. As the definition from Huang [38] and the Appendix $\mathrm{A}$ in $\mathrm{Xu}$ et al. [27] indicated, the EAGPE of each eddy is calculated as

$$
\mathrm{EAGPE}=\frac{\sum_{1}^{n} g^{2} \rho \eta_{i}^{2} A_{i}}{g^{\prime}}
$$

\section{Observation and Results}

Table 1 shows the mean wind speed, moving (or transit) speed, and central pressure of eight typhoons selected in the SCS. It also represents the eight typhoons passing through the corresponding preexisting CCE and remote sensing results of chl-a before and after the typhoon overlaid the CCE area. Table 2 gives the EKE and EAGPE changes of CCEs influenced by 8 typhoons. For Chanchu, the corresponding CCE below did not satisfy the 3rd criteria of eddy detection, so the EKE and EAGPE of that CCE were not included in Table 2. Here 2 typhoons, Leo and Hagibis, were addressed to show the chl-a response to typhoon in the CCE area and the change of CCE's EKE and EAGPE.

3.1. Typical Case: Typhoon Leo. Leo was the first typhoon assaulting the China mainland in 1999. After generating in the 


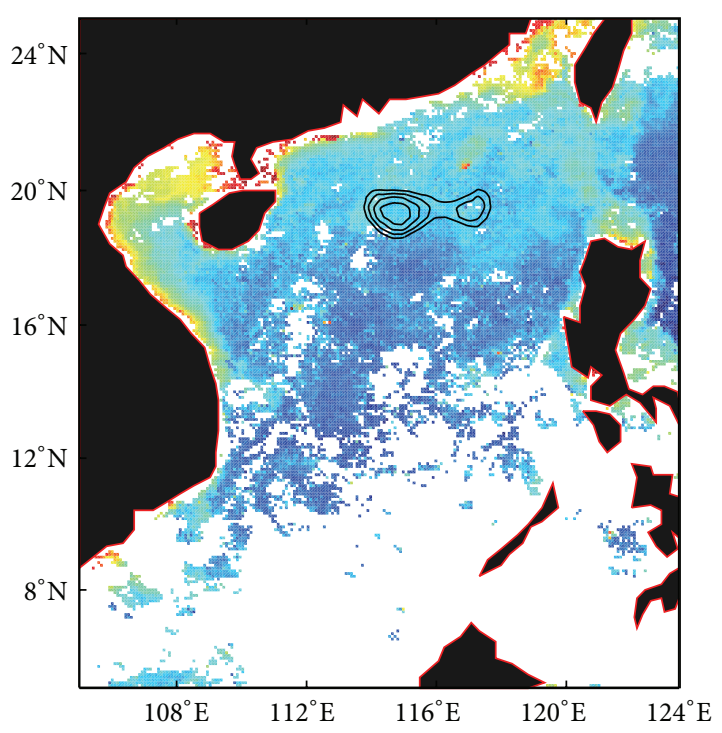

(a)

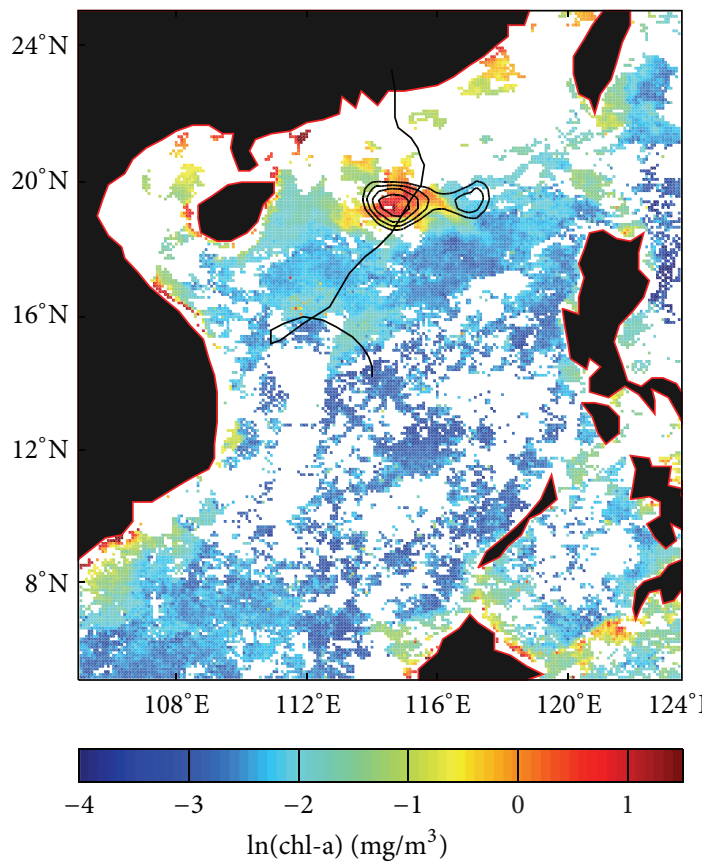

(c)

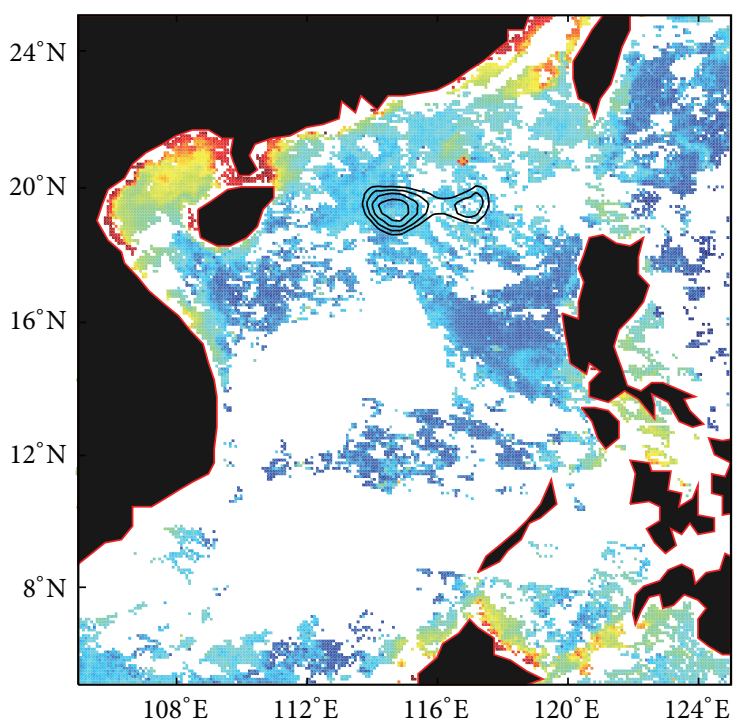

(b)

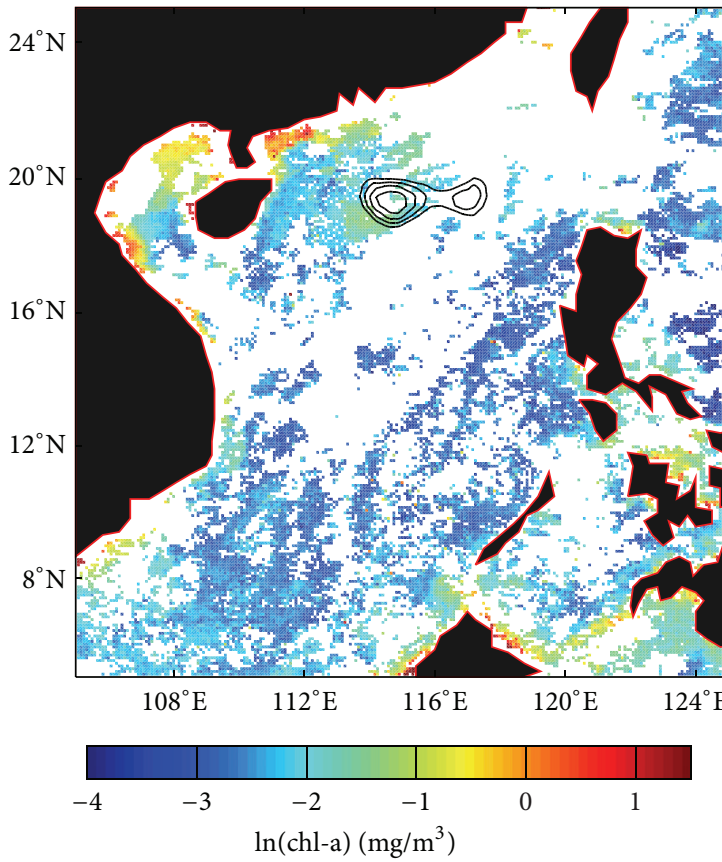

(d)

FIGURE 4: The chl-a concentration change under the influence of typhoon Leo in the CCE area. Colorbar is the natural logarithm value of chl-a concentration. (a), (b), (c), and (d) are the 8-day mean chlorophyll concentration derived from SeaWiFS in the SCS. (a) 15 April-22 April, 1999. (b) The prestorm chl-a distribution from 23 April to 30 April, 1999. (c) The poststorm chl-a distribution from 1 May to 8 May, 1999. The black solid line is the track of Leo. (d) 9 May-16 May, 1999. The contour indicates the CCE influenced by Leo. In (a), (b), (c), and (d), the CCE is the same one as on 30 April when CCE passed by Leo.

central part of the SCS on April 25, it moved northwestward as a tropical depression. By April 27, Leo began to shift northward and then completed a full circle with average maximum sustained winds of $17 \mathrm{~m} / \mathrm{s}$ around east of the Vietnam coast. During April 29, Leo moved to the northeast and intensified rapidly. By April 30, its maximum sustained winds were strengthened from $42 \mathrm{~m} / \mathrm{s}$ to $56 \mathrm{~m} / \mathrm{s}$. Its center passed through an ocean preexisting CCE (Figure 4(c)) with average moving speed $2.9 \mathrm{~m} / \mathrm{s}$ in the same day (April 30). The CCE had two centers. Its outmost contour value was $-8 \mathrm{~cm}$, and the minimum value was $-17.5 \mathrm{~cm}$ in the western center. Although Leo had affected the cold core eddy before April 30, as tropical cyclones' wind radius (class 7 wind speed $15 \mathrm{~m} / \mathrm{s}$ ) spanned $150 \mathrm{~km}$, the most important impact was exerted when Leo closed in on the eddy area. Thus, the typhoon average moving speed and average wind speed when the typhoon closed in 


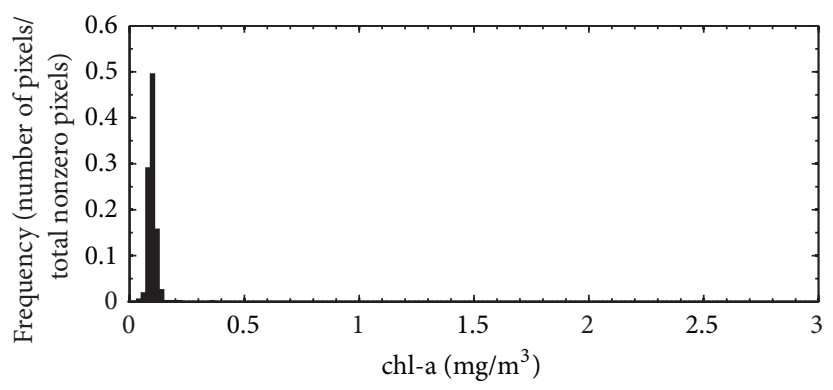

(a)

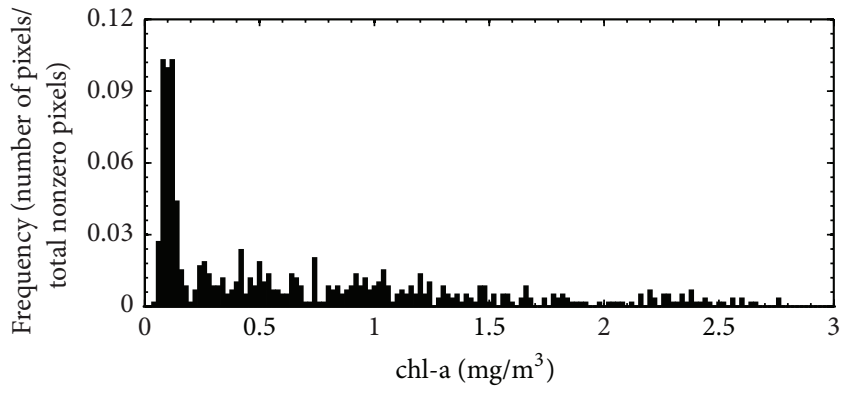

(b)

FIGURE 5: Frequency distribution of available chl-a pixel values in the CCE area derived from prestorm and poststorm images. (a) The prestorm chl-a distribution. (b) The poststorm chl-a distribution.

on the eddy area were calculated. Leo left the eddy area on May 1 and began to weaken and finally disappeared over the mainland.

Leo is a precise example to explain how to determine the prestorm and poststorm average chl-a concentration values in the eddy area. Three 8 -day, $9 \mathrm{~km}$, and level 3 SeaWiFS chla data were used according to the period when Leo persisted. Leo occurred between April 25 and May 3. The chl-a data are shown in Figures 4(b) and 4(c), and time scales are shown separately from April 23 to April 30 and from May 1 to May 8. In fact, Leo began to influence the marked eddy area before April 30; however, due to the fact that high chl-a which is a response to a typhoon usually delayed several days (e.g., 3-4 days, Walker et al. [13]), phytoplankton bloom did not exist in prestorm conditions from April 23 to April 30 (Figures 4(a) and 4(b)), and the obvious increase of chl-a is present in Figure 4(c) in CCE region. The first 8-day data (from April 23 to April 30) was set as "prestorm," and the second 8-day data (from May 1 to May 8) as "post-storm."

The general characteristic of chl-a spatial distribution is that chl-a concentration is higher in coastal waters and is lower in offshore waters (Figures 4(a) and 4(b)) [39]. The CCE was located in the northern continental slope of SCS where the chl-a was higher than the central ocean region. Before the effects of typhoon Leo, the average chl-a calculated in the eddy area from April 15 22 and from April 23 30 was, respectively, $0.1111 \mathrm{mg} / \mathrm{m}^{3}$ and $0.1113 \mathrm{mg} / \mathrm{m}^{3}$ (Figures 4 (a) and $4(\mathrm{~b}))$. The difference is only $0.0002 \mathrm{mg} / \mathrm{m}^{3}$. Although it is hard to determine whether the variation $0.0002 \mathrm{mg} / \mathrm{m}^{3}$ was caused by Leo, the variation can be neglected when compared with the increase of chl-a in CCE after typhoon (Figure 4(c)). Figure 4(c) shows that the typhoon track has passed the CCE area, and the chl-a obviously increased in the CCE area (Figure 4(c)). It is noted that higher chl-a values were mainly present on the western center of CCE area, which is closer to the typhoon center (Figure 4(c)), rather than on the right side of the storm track. The poststorm average chl-a was up to $0.7174 \mathrm{mg} / \mathrm{m}^{3}$, more than 6 times greater than that before typhoon. An area of more than $14,400 \mathrm{~km}^{2}$ had chl-a higher than $1 \mathrm{mg} / \mathrm{m}^{3}$. The region surrounded by $-14 \mathrm{~cm}$ contour around the western center covered roughly $12,000 \mathrm{~km}^{2}$, where average chl-a concentration was as high as $1.7371 \mathrm{mg} / \mathrm{m}^{3}$. But before Leo, it was about $0.1069 \mathrm{mg} / \mathrm{m}^{3}$ in the same region. The high chl-a did not last for long, as it rapidly decreased to $0.1605 \mathrm{mg} / \mathrm{m}^{3}$ from May 9 to May 16 (Figure 4(d)) which was very close to the level before typhoon Leo.

Figure 5 is the frequency distribution of pretyphoon and posttyphoon chl-a in the CCE area. Before Leo, 76\% chla concentration values mainly concentrated within a small range from 0.08 to $0.12 \mathrm{mg} / \mathrm{m}^{3}$; after Leo, these values became dispersive. About $19 \%$ of pixel values fell within the range of 0.08 to $0.12 \mathrm{mg} / \mathrm{m}^{3} ; 28 \%$ of pixel values were more than $1 \mathrm{mg} / \mathrm{m}^{3}$. It indicates that chl-a concentration values are relatively uniform before typhoon; after typhoon passage, chl-a values obviously increased in various amplitudes in different regions in the CCE area.

Figure 6 shows the area of associated CCE before and after typhoon Leo. The CCE was generated in local position and intensified by cyclonic wind stress of the typhoon. On the SSHA images in Figure 4(b), eddies presented a series of closed contours. The horizontal distance and height difference between the amplitude and the outermost contour of eddy separately implies eddy's area and intensity of cyclonic circulation. The intensification of CCE diagnosed from SSHA data is represented by expansion of the CCE's area and the deepening of SSHA. On April 28 before Leo, the CCE's outermost contour value was shown to be $-7 \mathrm{~cm}$ and minimum amplitude at center was $-15 \mathrm{~cm}$ (Figure 6(a)). The CCE covered approximately $66,700 \mathrm{~km}^{2}$. By May 5 after Leo passed, the outermost contour of CCE became $-11 \mathrm{~cm}$; minimum amplitude at center deepened to $-25 \mathrm{~cm}$; its area expanded to $75,500 \mathrm{~km}^{2}$ (Figure 6(b)). It is easy to see that CCE was intensified by Leo from the change of the SSHA. However, the description above is not clear enough and ignores the volume effects of CCE. Thus, the intensification was further described by EKE and EAGPE. The SSHA data on April 28 were used to calculate prestorm energy. EKE and EAGPE, respectively, were $1.70 \times 10^{14} \mathrm{~J}$ and $1.13 \times 10^{15} \mathrm{~J}$. The poststorm energy was calculated based on the SSHA at the region of CCE on May 5, which is 4 days after typhoon. (Hereafter, the same method is used to calculate EKE and EAGPE for other typhoons.) Poststorm EKE and EAGPE grew significantly, and they were 1.8 and 4.6 times, respectively, larger than those on April 28 (see Table 2). In this case, 


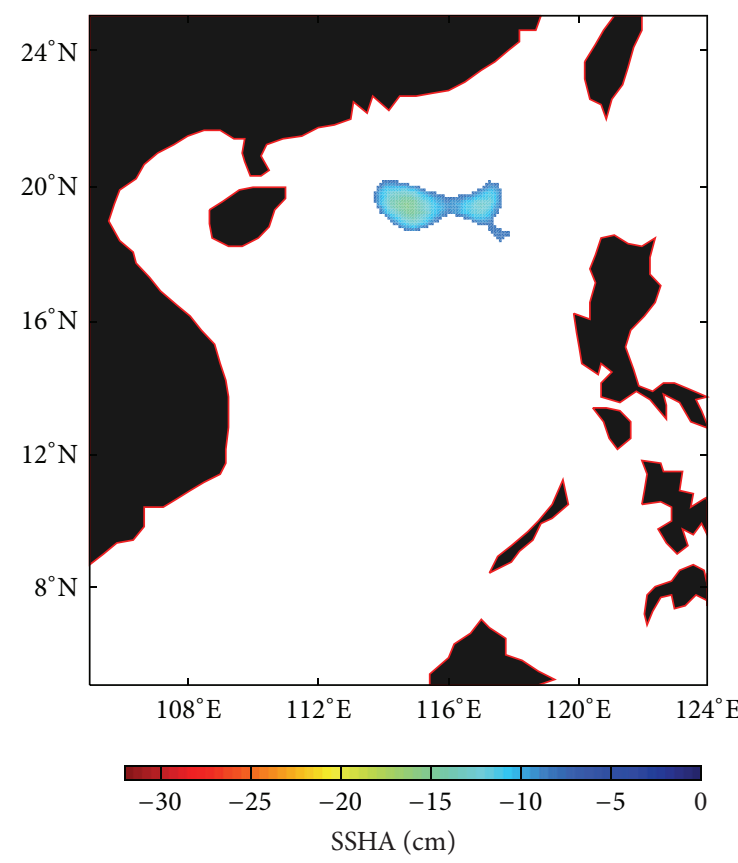

(a)

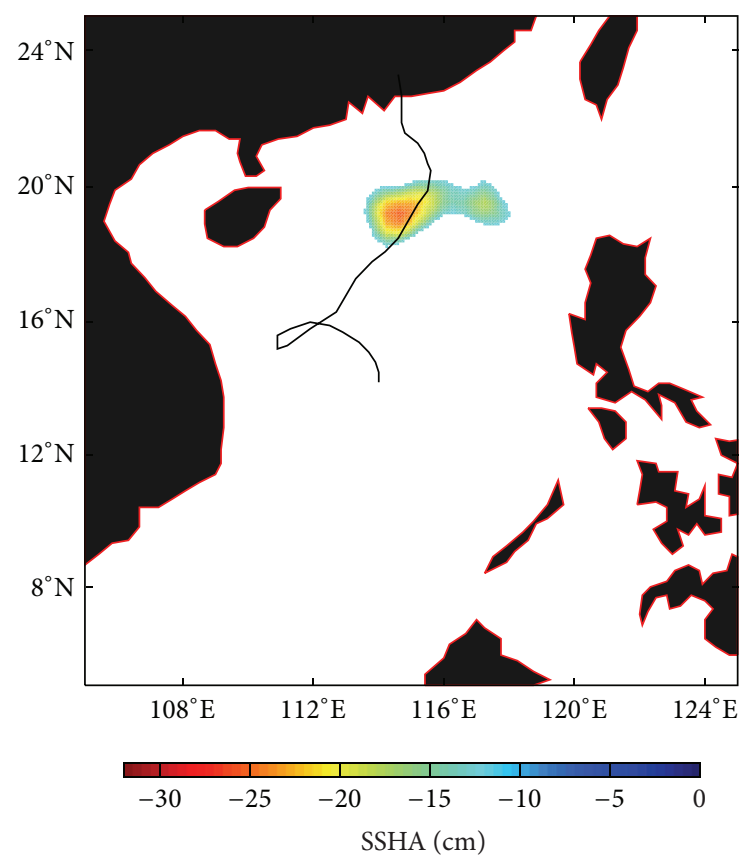

(b)

Figure 6: The SSHA images show the CCE which was passed by typhoon Leo. (a) SSHA on 28 April, 1999. (b) SSHA on 5 May, 1999. The black solid line is the track of Leo.

the CCE enhanced by Leo can be quantitatively calculated; the CCE extracted much more EAGPE energy than EKE.

3.2. Typical Case: Typhoon Hagibis. Typhoon Hagibis showed a special track (Figure 7(b)). Hagibis was generated over the east Pacific Ocean on November 18, 2007, near $8.6^{\circ} \mathrm{N}$, $128^{\circ} \mathrm{E}$. After crossing the Philippines as a tropical depression, Hagibis entered into SCS and upgraded to a tropical storm soon after. The tropical storm meandered northwest across the northern part of SCS and continued to intensify. On November 21, the storm strengthened into typhoon status and then gradually approached a CCE region to the southeast of the coast of Vietnam. Hagibis did not keep moving northwest but wobbled off the coast of Vietnam on November 22 and gradually weakened in the eastward track. By November 23, the storm turned back eastward in the SCS towards the Philippines once again. It weakened to a depression and disappeared in the east of the Philippines on November 27. Hagibis's center entered a CCE area on November 22, with a radius of $320 \mathrm{~km}$ and class 7 wind speed of $15 \mathrm{~m} / \mathrm{s}$. It stopped its eastward movement over the CCE area. The typhoon center left the CCE area on November 25 (Figure 7(b)). The SSHA data on November 24, when Hagibis began to turn back, were used to fix the CCE location. The outermost edge of this CCE was surrounded by $0 \mathrm{~m}$ contour; its minimum SSHA is $-20 \mathrm{~cm}$, and the eddy covered approximately $143,200 \mathrm{~km}^{2}$.

From November 17 24, the CCE area was covered by cloud so extensively that seldom chl-a information was able to be obtained from this area. The previous data from November 9 16 were chosen to represent the prestorm stage. The average chl-a concentration of prestorm was shown as $0.1145 \mathrm{mg} / \mathrm{m}^{3}$
(Figure 7(a)), which is consistent with the general range 0.1 $0.2 \mathrm{mg} / \mathrm{m}^{3}$. Compared with Sun et al's result [40] which is $0.14 \mathrm{mg} / \mathrm{m}^{3}$ diagnosing by the MODIS data (the area Sun et al. [40] used to calculate average chl-a concentration is larger than ours), the value of prestorm concentration is rational. From November 25 to December 2, the chl-a in the CCE area increased greatly, and the average chl-a was up to $1.4338 \mathrm{mg} / \mathrm{m}^{3}$. The area of chl-a whose values were higher than $1 \mathrm{mg} / \mathrm{m}^{3}$ was larger than $64,370 \mathrm{~km}^{2}$. The high chl-a was mainly located on the eddy center (Figure $7(\mathrm{~b})$ ). The chl-a value was still very high until the next 8 -day period from December 3 10. The average chl-a concentration became $0.9464 \mathrm{mg} / \mathrm{m}^{3}$ and the area of that concentration more than $1 \mathrm{mg} / \mathrm{m}^{3}$ exceeded $34,500 \mathrm{~km}^{2}$.

The CCE changes on the SSHA image were shown in Figures 7(c) and 7(d). The prestorm SSHA data on December 21 showed a CCE whose outermost contour value was $0 \mathrm{~m}$ and the minimum SSHA value was $-14 \mathrm{~cm}$ and an area covered by cyclonic circulation (Figure 7(c)). On December 28 after Hagibis, the two cyclonic circulations merged into a new larger CCE (Figure 7(d)). Its minimum SSHA value deepened from -14 to $-29 \mathrm{~cm}$, while the area that CCE covered was two times as large as the area before typhoon. It is noted that, first, the speed of typhoon Hagibis was slowest, and second Hagibis' special track (Figure 7(d)) made the typhoon center stay over the region of CCE for a much longer time than typhoon Leo. These two factors make Hagibis overlay over the CCE for the longest forcing time, greatly enhancing CCE. The poststorm EKE was 3.4 times larger than the prestorm EKE, while the poststorm EAGPE was about 8.8 times larger than 


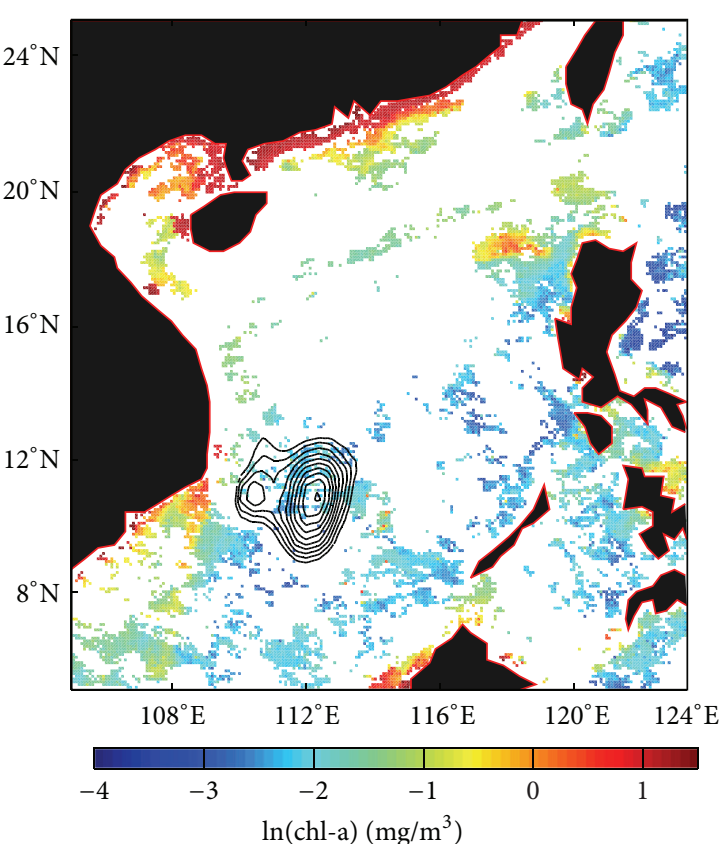

(a)

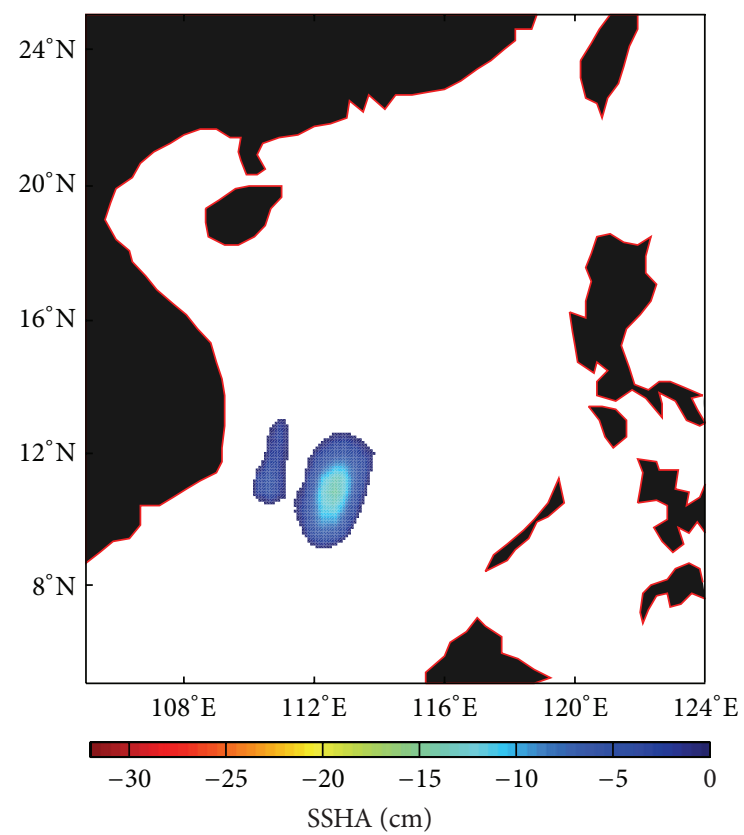

(c)

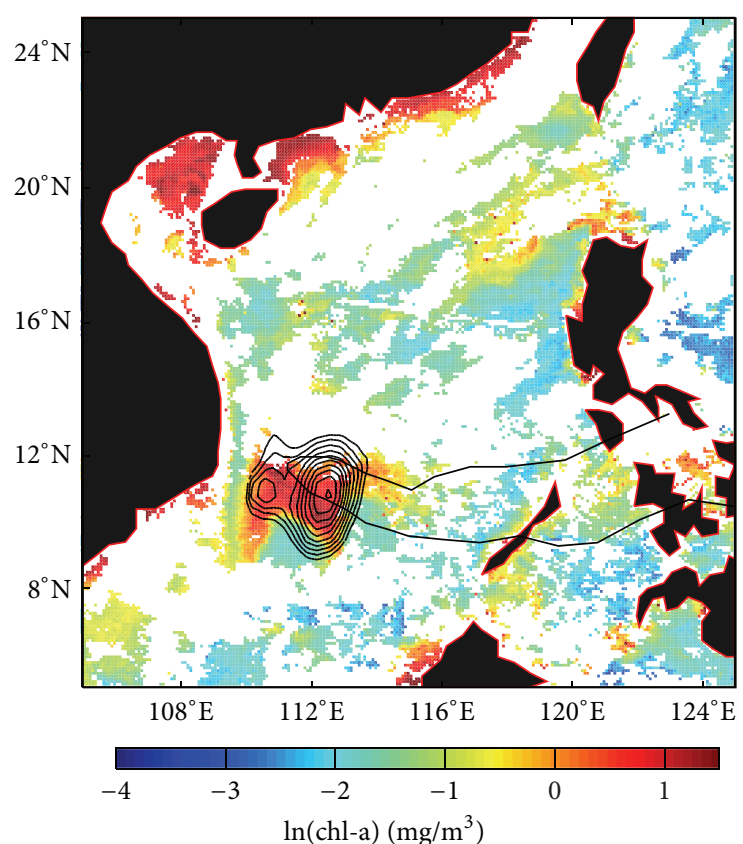

(b)

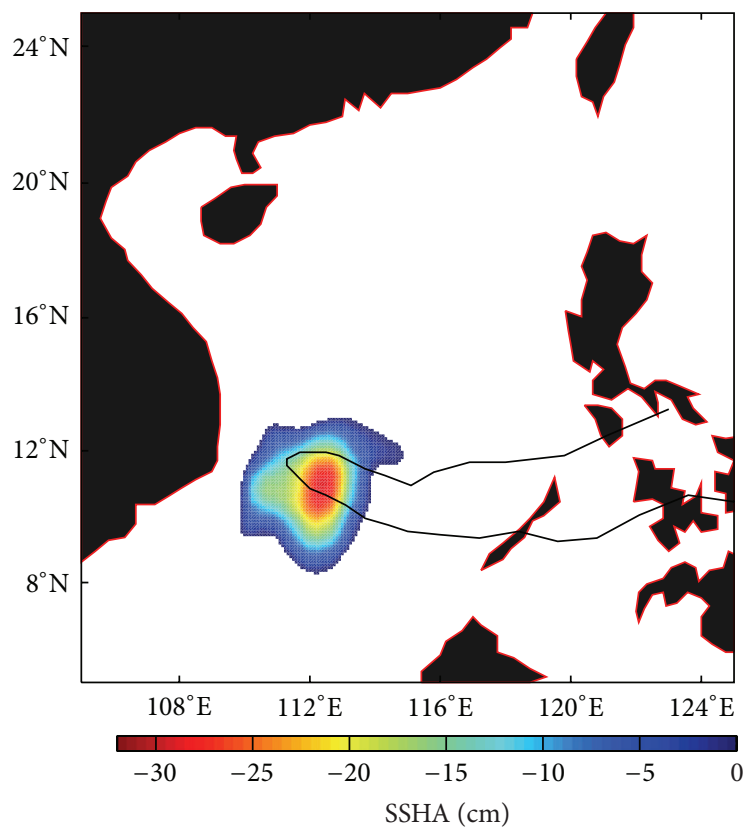

(d)

FIgURE 7: (a)-(b) The change of chl-a concentration under the influence of typhoon Hagibis in the CCE area. Colorbar is the natural logarithm value of chl-a concentration. The closed contour indicates the CCE area on 24 November. (a) Prestorm chl-a distribution from 9 November to 16 November, 2007. (b) The poststorm chl-a distribution from 25 November to 2 December, 2007. (c)-(d) The change of CCE under the influence of typhoon Hagibis. (c) The SSHA image shows the CCE on 21 November before typhoon Hagibis. (d) The SSHA image shows the CCE on 28 November after typhoon Hagibis. The thick black solid line in figures (b) and (d) is the track of Hagibis.

the prestorm one. The large baroclinic EKE and EAGPE of poststorm CCE extracted from Hagibis indicate that typhoon Hagibis intensified the energy of the associated CCEs and made the two prestorm CCEs unstable and finally combined them into one CCE. Compared with typhoon Leo, EKE and EAGPE of the associated CCE were greatly enhanced by Hagibis, especially the EAGPE of CCE was dominantly enhanced.

3.3. Other Typhoons. Similar methods were used to calculate the change of chl-a and CCEs' energy under the influence of other six typhoons. According to the JTWC, Nanmadol, 
TABLE 3: The prestorm and poststorm dates corresponding to Figure 11 for SST differences.

\begin{tabular}{lccc}
\hline $\begin{array}{l}\text { Typhoon's } \\
\text { name }\end{array}$ & $\begin{array}{c}\text { Prestorm } \\
\text { day/month/year }\end{array}$ & $\begin{array}{c}\text { Pass by CCE time } \\
\text { day/month/year }\end{array}$ & $\begin{array}{c}\text { Poststorm } \\
\text { day/month/year }\end{array}$ \\
\hline Leo & $24 / 04 / 99$ & $30 / 04 / 99$ & $01 / 05 / 99$ \\
Lingling & $04 / 11 / 01$ & $10 / 11 / 01$ & $11 / 11 / 01$ \\
Nanmadol & $29 / 11 / 04$ & $03 / 12 / 04$ & $06 / 12 / 04$ \\
Kai-tak & $26 / 10 / 05$ & $30 / 10 / 05$ & $01 / 11 / 05$ \\
Chanchu & $06 / 05 / 06$ & $16 / 05 / 06$ & $17 / 05 / 06$ \\
Durian & $23 / 11 / 06$ & $03 / 12 / 06$ & $04 / 12 / 06$ \\
Utor & $05 / 12 / 06$ & $12 / 12 / 06$ & $18 / 12 / 06$ \\
Hagibis & $18 / 11 / 07$ & $24 / 11 / 07$ & $26 / 11 / 07$ \\
\hline
\end{tabular}

Kai-tak, Chanchu, Durian, Utor, and Lingling were selected typhoons before they overlaid eddies. The associated CCEs which were overlaid by typhoons mentioned above and prestorm chl-a are shown in Figure 8 while Figure 9 shows chl-a concentration after typhoon exerted its influence on sea and corresponding typhoon tracks. Nanmadol is the only case in which the typhoon center did not pass through the CCE. Durian and Utor passed through the same CCE successively. The detailed typhoon information during the period that they overlaid corresponding CCEs is shown in Table 1 while Table 3 shows the prestorm and poststorm dates corresponding to each typhoon. Table 3 also shows the time when typhoons passed through their corresponding CCEs.

According to Table 1, four typhoons kept a slow transit speed of less than $3 \mathrm{~m} / \mathrm{s}$. Especially for Hagibis and Kai-tak, the transit speeds were less than $2.2 \mathrm{~m} / \mathrm{s}$. Six typhoons had a strong maximum mean wind speed of more than $40 \mathrm{~m} / \mathrm{s}$ when they passed through the CCE areas. Nanmadol had the fastest transit speed of $6.4741 \mathrm{~m} / \mathrm{s}$ and it was the only one whose center did not directly pass through the corresponding CCE. Chanchu was the strongest typhoon with maximum wind speed of $59.676 \mathrm{~m} / \mathrm{s}$ when it was over the CCE.

Before typhoons overlaid the CCEs, the chl-a in the CCE region corresponding to Chanchu (see Figure 8) had the lowest value, which matches the average value in spring. In this season, the center basin of the SCS is oligotrophic. On the contrary, the chl-a in the CCE region corresponding to Kai-tak (see Figure 8) had a higher prestorm value, since the CCE was located to the eastern Vietnam coast where the high prestorm chl-a was induced by monsoons. The chla in the CCE region corresponding to Nanmadol was also higher, since the chl-a concentration in the northern SCS is higher in winter. It is noted that the chl-a was obviously high to the north of the CCE region, where upwelling effects were induced by the northeasterly monsoons around the Philippine Island. For Lingling, Durian, and Utor, the corresponding CCEs were in the center basin of the SCS like the scenario of Chanchu, but the chl-a in those CCEs were higher than those of Chanchu. It is because the chl-a concentration in winter is higher than that in spring.

Table 1 shows that, in general, the chl-a average in preexisting CCE was between 0.08 and $0.20 \mathrm{mg} / \mathrm{m}^{3}$ before typhoons' influence. After typhoons, the chl-a average was different (see Figure 9), changing from 0.2454 to $1.4338 \mathrm{mg} /$ $\mathrm{m}^{3}$ (see Table 1). It is emphasized that typhoon Durian first passed through the region of a CCE during December 3 10, 2006, and then Utor passed through the same CCE region from December 11 18, 2006. Due to typhoons continuously passing through the same region of CCE, the prestorm EKE and EAGPE of the CCE before typhoon Utor were strong. However, the chl-a increases induced by Durian and Utor were in different regions of CCE, which did not interfere with each other. These results were also shown both in SeaWiFS and MODIS chl-a data. To eliminate the interference of Durian on the data of prestorm chl-a of Utor, the chl-a data from 25 November to 2 December as the prestorm chl-a of Utor was used, same as Durian's, instead of the data from December 3 10.

Because cyclonic circulation before the influence of typhoon Chanchu on May 10, 2006, did not meet the criteria of eddy detection, the prestorm EKE and EAGPE of CCE were not able to be calculated. Table 2 shows that the order of CCE's EKE and EAGPE was $10^{14} \sim 10^{15} \mathrm{~J}$. By comparing the prestorm and poststorm CCE energy, almost all eddies were enhanced by the influence of typhoons (Table 2). The exception of a reduced EKE was the scenario of typhoon Durian, when EKE was calculated from November 29 to December 6. The CCE had two cores separately located in the north and south of the CCE area. Durian passed through the CCE on December 3. By December 6, the northern core disappeared. The southern core of CCE was closer to the typhoon track as it was intensified. The new eddy with lower spin velocity had decreased EKE, while its EAGPE still increased. In other cases, the poststorm EAGPE was always more enhanced than the poststorm EKE. The minimum energy increases occurred in Nanmadol, whose center did not directly pass through the CCE and whose transit speed was rapidest. The maximum EAGPE increases occurred in Hagibis, which had slower transit speed with the longest effect on CCE.

3.4. Analysis of EKE, EAGPE, and chl-a in CCE. The scenarios of typhoon over CCE are so few that the effects of transit speed of typhoons are only examined here. In the CCE, a typhoon with slower transit speed induces greater chla change. Figure 10 shows that the lower transit speeds of Hagibis, Kai-tak, and Leo are corresponding to the higher ratios of poststorm chl-a/prestorm chl-a with value of 12.5, 4.9, and 6.6, poststorm EKE/prestorm EKE with value of 3.4, 5.0, and 2.2, and poststorm EAGPE/prestorm EAGPE with value of $8.9,3.8$, and 3.1. It is obvious that the ratio of poststorm EAGPE/prestorm EAGPE and the ratio of poststorm chl-a/prestorm chl-a decrease monotonously. It is clear the chl-a, EKE, and EAGPE in CCE regions are able to be enhanced by the typhoon with slow transit speed. Especially when the typhoon Hagibis interacted on CCE for a long time, the EAGPE and chl-a were greatly enhanced. However, though Lingling is a strong typhoon, the ratio of poststorm EKE/prestorm EKE is not as large as those of typhoon with slow transit speeds. Nanmadol, Utor, Durian, and Lingling with higher transit speeds are corresponding to the lower ratios of poststorm chl-a/prestorm chl-a with value of 2.9, 2.2, 2.3, and 3.9, poststorm EKE/prestorm EKE with value of 1.3, 


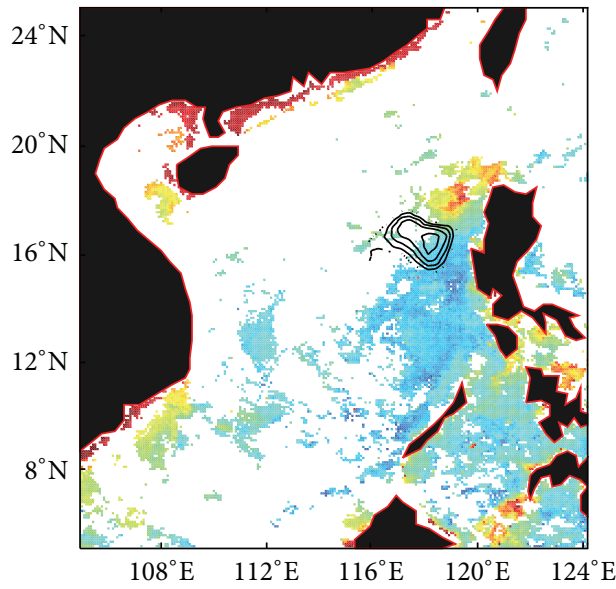

(a) Nanmadol

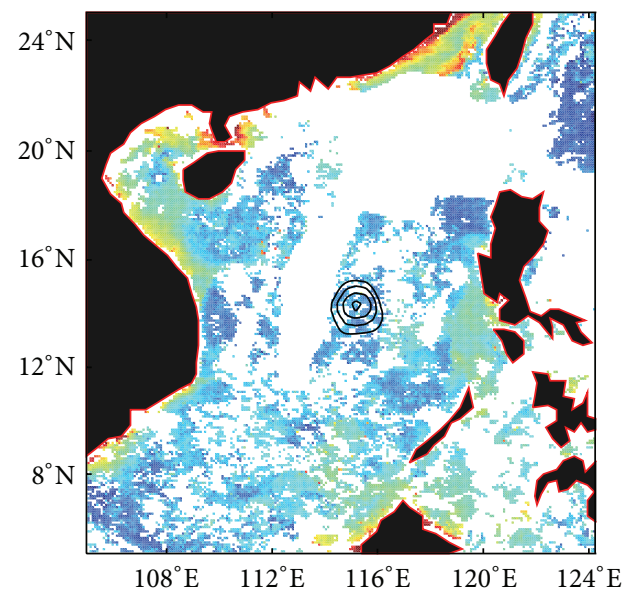

(c) Chanchu

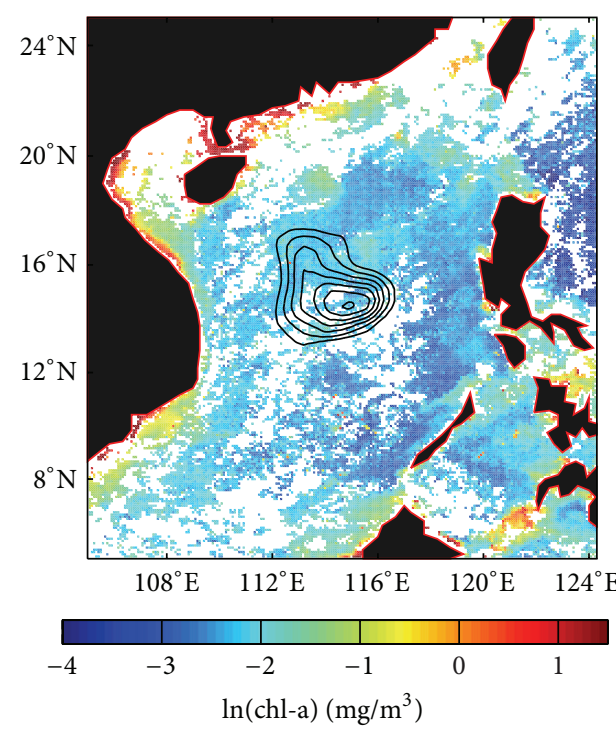

(e) Utor

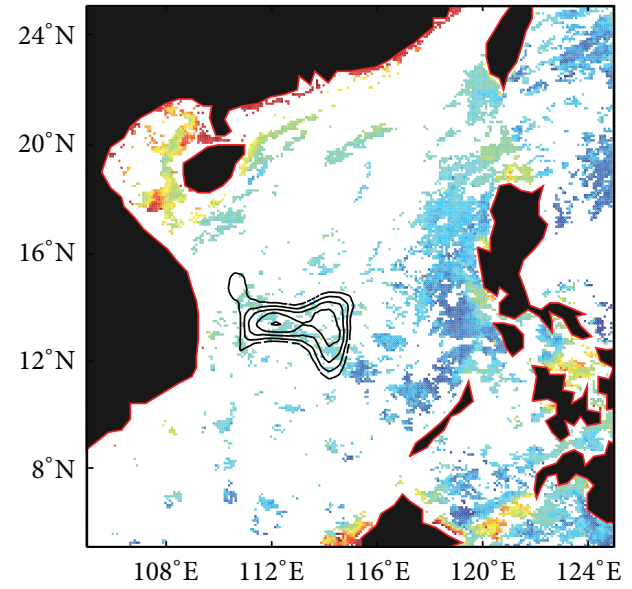

(b) Kai-tak

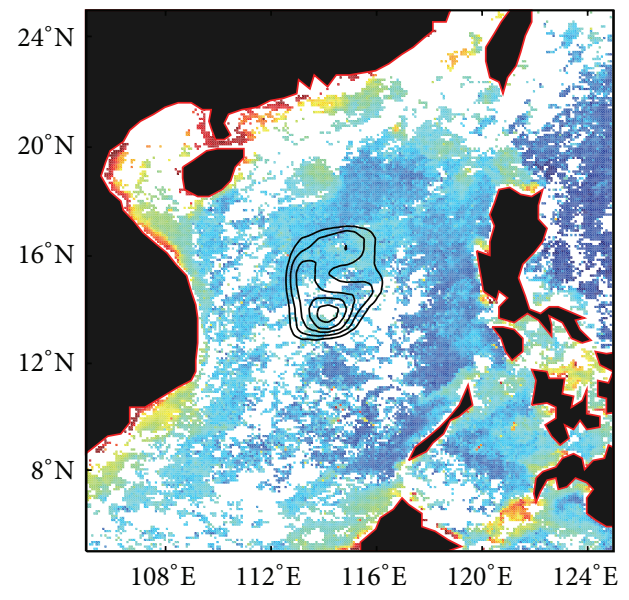

(d) Durian

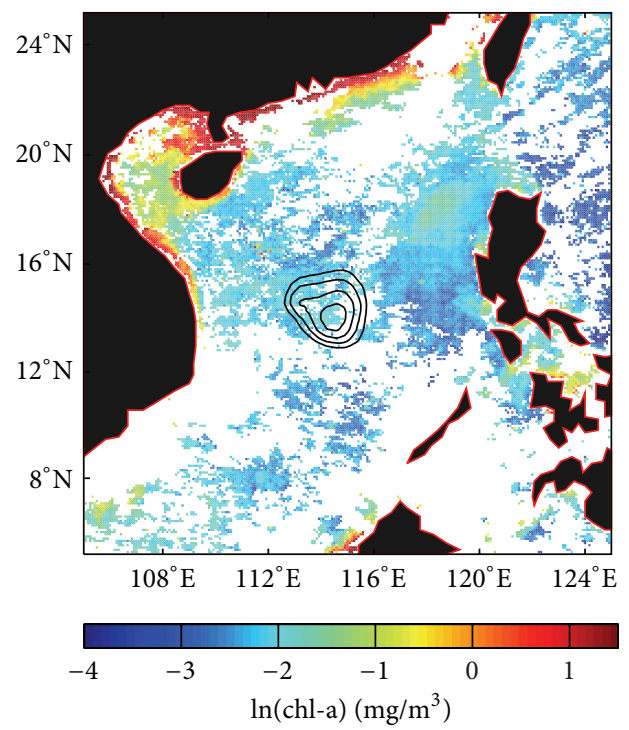

(f) Lingling

FIGURE 8: The chl-a concentration in preexisting CCEs before typhoons. Colorbar is the natural logarithm value of chl-a concentration. 


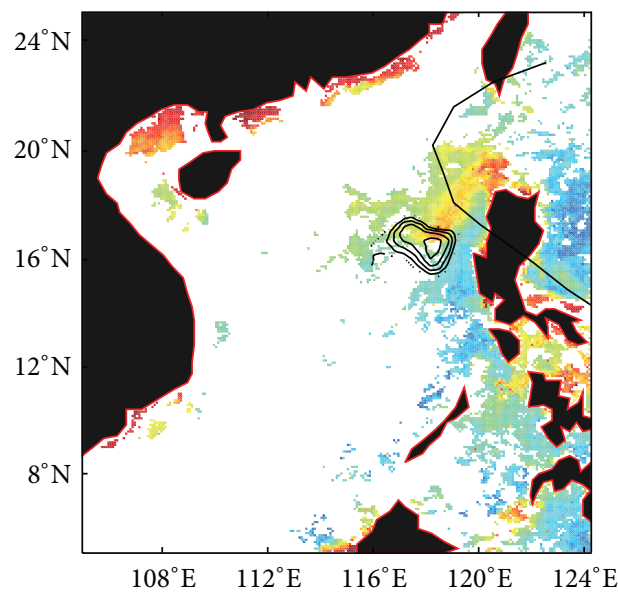

(a)

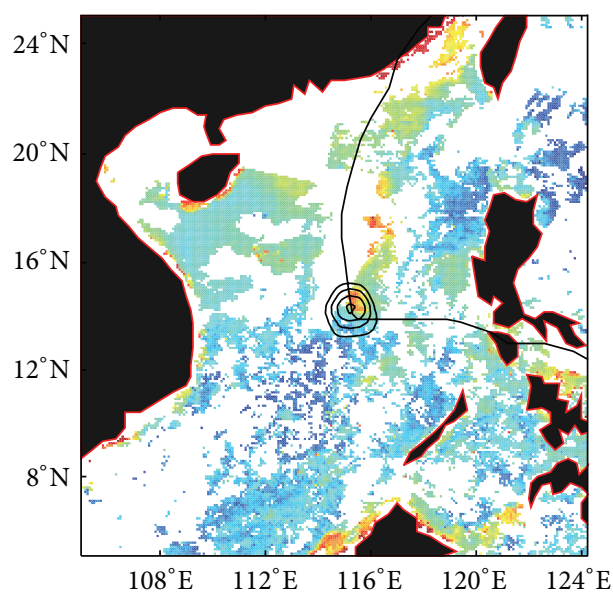

(c)

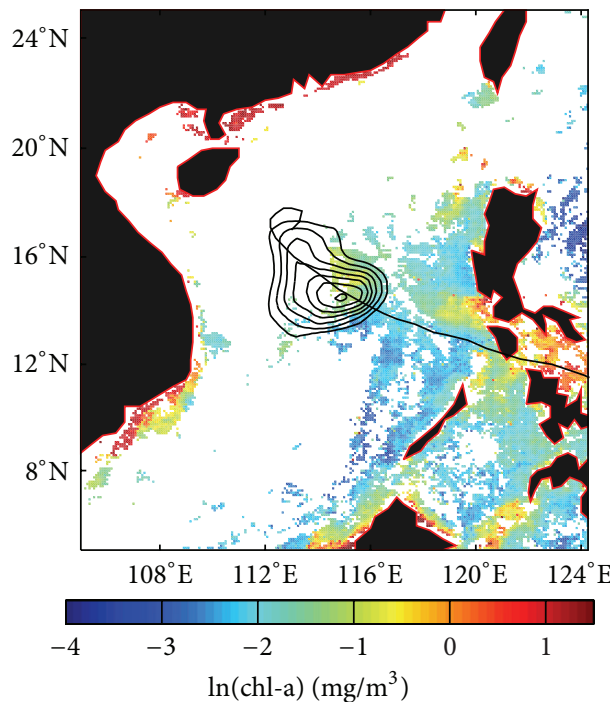

(e)

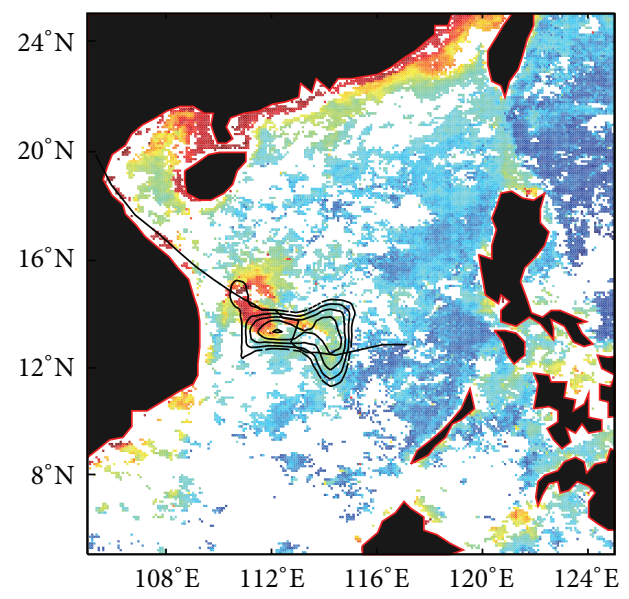

(b)

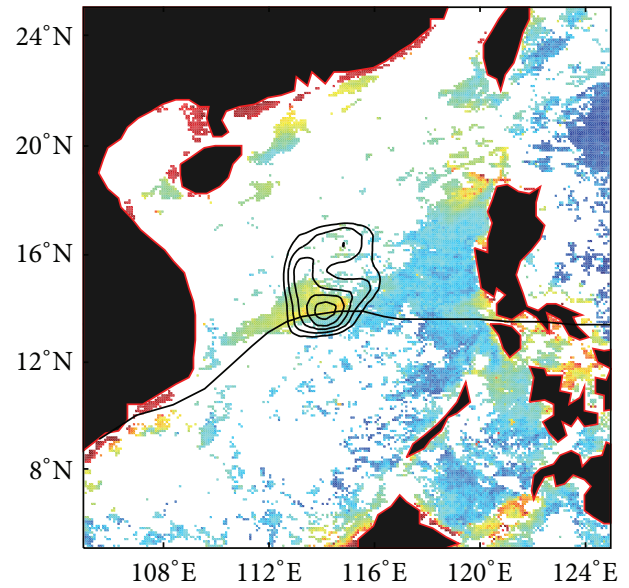

(d)

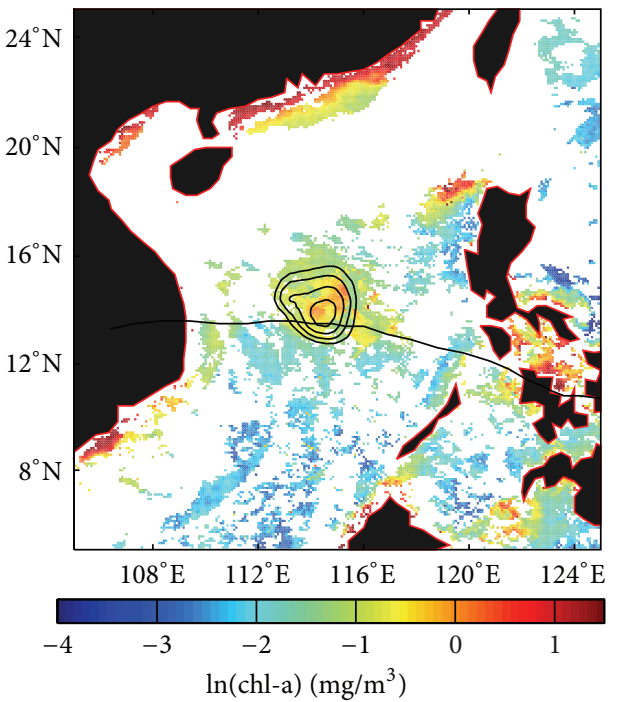

(f)

FIGURE 9: The chl-a blooms under the influence of typhoons in the CCE area. Colorbar is the natural logarithm value of chl-a concentration. The thick black solid lines in figures are typhoon tracks. The closed contours are the CCEs influenced by typhoons. (a) Typhoon Nanmadol in December 2004. chl-a concentration is from 2 December to 9 December. (b) Typhoon Kai-tak in November 2005, and chl-a concentration is from 1 November to 8 November. (c) Typhoon Chanchu in May 2006, and chl-a concentration is from 17 May to 24 May. (d) Typhoon Durian in December 2006, and chl-a concentration is from 3 December to 10 December. (e) Typhoon Utor in 2006, and chl-a concentration is from 11 December to 18 December. (f) Typhoon Lingling in 2001, and chl-a concentration is from November 9 to November 16. 


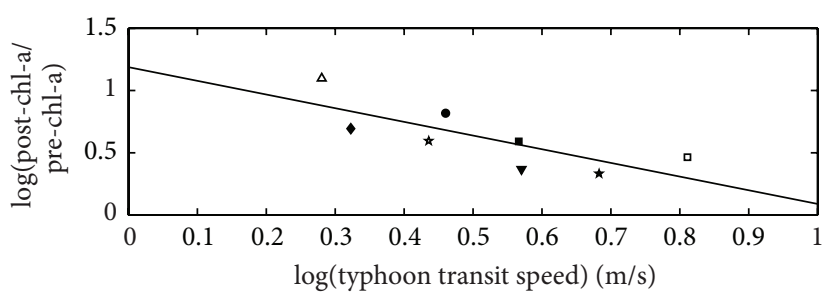

(a)

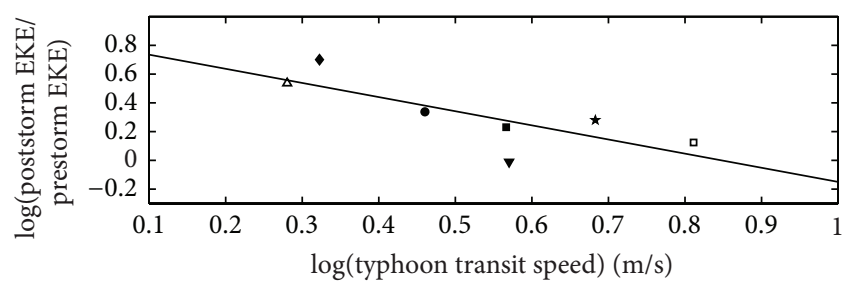

(b)

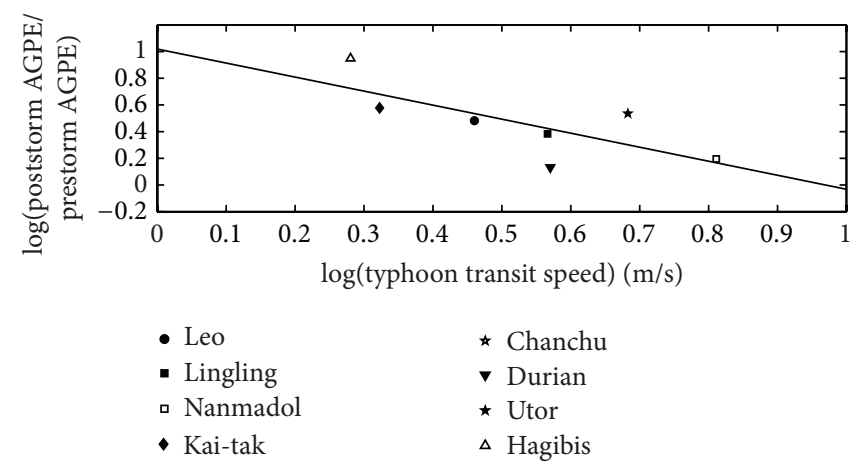

(c)

FIGURE 10: The ratio of poststorm (a) chl-a, (b) EKE, and (c) EAGPE to prestorm chl-a, EKE, and EAGPE, respectively, versus typhoon transit speed in logarithm coordinate.

1.9, 1.3, and 1.7, and poststorm EAGPE/prestorm EAGPE with value of 1.6, 3.4, 1.6, and 2.4.

Comparing EAGPE with EKE, EAGPE is much higher than EKE regardless of both prestorm or poststorm (see Table 2). EAGPE is considered as a dominant physical parameter to describe the changes of CCEs' response to typhoons. Why the poststorm EAGPE is enhanced is able to be attributed to many reasons. First, the wind stress curl of typhoon has the same polarity as the vorticity of cold eddies. Second, the wind stress vector turns clockwise as typhoon passes by on the right side of its track in the Northern Hemisphere. Hence the divergence of horizontal circulation will be enhanced, which may induce a significant horizontal pressure gradient towards the center of cold eddy. It implies that the amplitude of the SSHA in the core of cold eddy will increase, meaning the EAGPE is increased significantly. Meantime, the upper-layer deepening is able to be induced by intensified turbulent mixing under the circumstance of typhoon [36] but note that this effect is not involved in the calculation of EAGPE.

In fact, SST is a key physical factor to indicate the chla increase. The more the EAGPE changes, the higher the isotherms/isopycnals rise in the core of cyclonic eddy, which produces an easier condition for SST cooling. Thus, strengthened EAGPE may have lower SST in the center of the CCE and larger chl-a concentration. Figure 11 shows the SST change under the influence of typhoon in the CCE area. The maximum SST cooling, which can reach $3 \sim 9^{\circ} \mathrm{C}$, always occurred 1 2 days after typhoons passed by the CCE. In the other regions along the typhoon tracks, the SST cooling was usually less than $3^{\circ} \mathrm{C}$. Except Kai-tak, chl-a bloom corresponded well with the SST cooling position for the other seven typhoons. Especially in the cases of Durian and Utor, the largest SST cooling mainly occurred on the right side of the typhoon track in the CCE area and in different regions of the same CCE area, which is consistent with the chl-a bloom in the positions separately caused by Durian and Utor. For Kai-tak, the distribution of the cooling SST in the CCE does not superpose the area of larger chl-a concentration, and thus a reasonable explanation cannot be found for this result (see Figure 11(d)).

Figures 11(b), 11(d), 11(e), and 11(h) show that variations of SST were able to reach $6 \sim 9^{\circ} \mathrm{C}$. The SST in the center of CCE was cooled down to $\sim 7.9^{\circ} \mathrm{C}$ by typhoon Hagibis. The EAGPE was greatly enhanced and the poststorm EAGPE had larger value of $5.76 \times 10^{15} \mathrm{~J}$, and the difference in EAGPE (poststorm EAGPE - prestorm EAGPE) was $5.11 \times 10^{15} \mathrm{~J}$. The SSTs in the center of the CCE were also cooled down to $\sim 8^{\circ} \mathrm{C}$ by typhoons Lingling and Kaitak, and the enhanced EAGPE of CCE had a larger value of $2.46 \times 10^{15} \mathrm{~J}$ and $5.65 \times 10^{15} \mathrm{~J}$, and the corresponding difference in EAGPE of CCE was $1.81 \times$ $10^{15} \mathrm{~J}$ and $3.31 \times 10^{15} \mathrm{~J}$, respectively. Though typhoon Utor had a small SST cooling at the center of the CCE, the Durian and Utor typhoons continuously forced on the same CCE; thus, both Durian and Utor cooled down SST to roughly $\sim 7^{\circ} \mathrm{C}$ and enhanced the EAGPE from $1.11 \times 10^{15}$ to $5.17 \times 10^{15} \mathrm{~J}$, which generated the EAGPE difference of $4.06 \times 10^{15} \mathrm{~J}$ in the CCE. Leo cooled down the center SST of the CCE to $4 \sim 5^{\circ} \mathrm{C}$, and the ratio of poststorm EAGPE/prestorm EAGPE was 3. The difference in EAGPE of the CCE was $2.3 \times 10^{15} \mathrm{~J}$. Nanmadol's track did not pass through the center of the CCE, and the SST of the CCE was cooled down to only $3^{\circ} \mathrm{C}$. The difference in EAGPE of the CCE was $1.64 \times 10^{15} \mathrm{~J}$. Hence, qualitatively, 


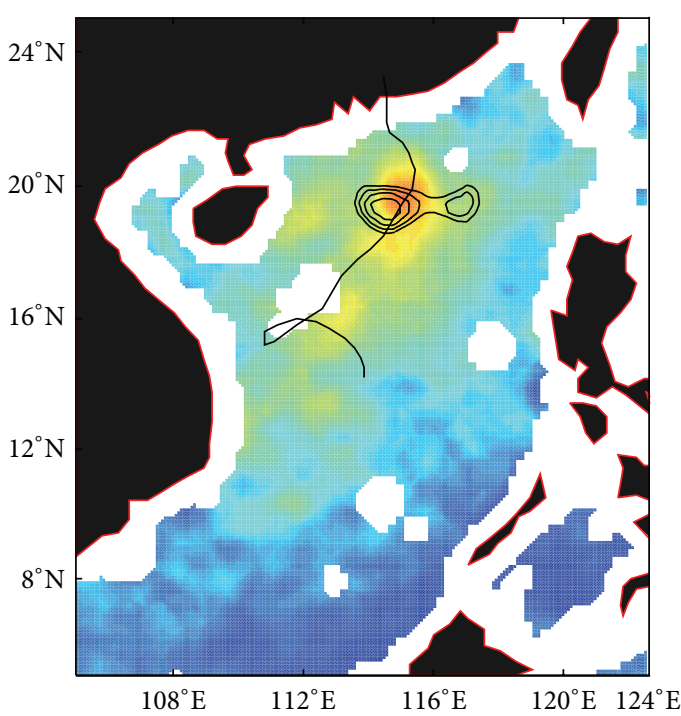

(a)

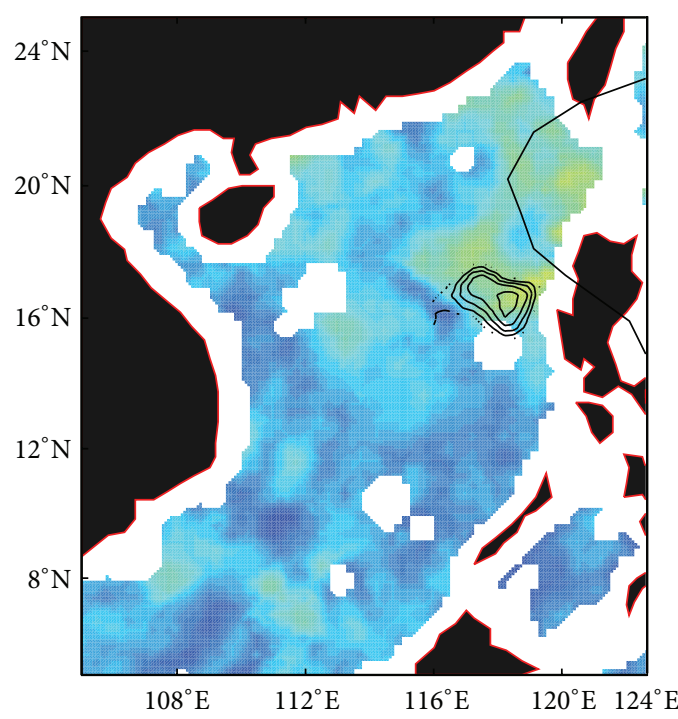

(c)

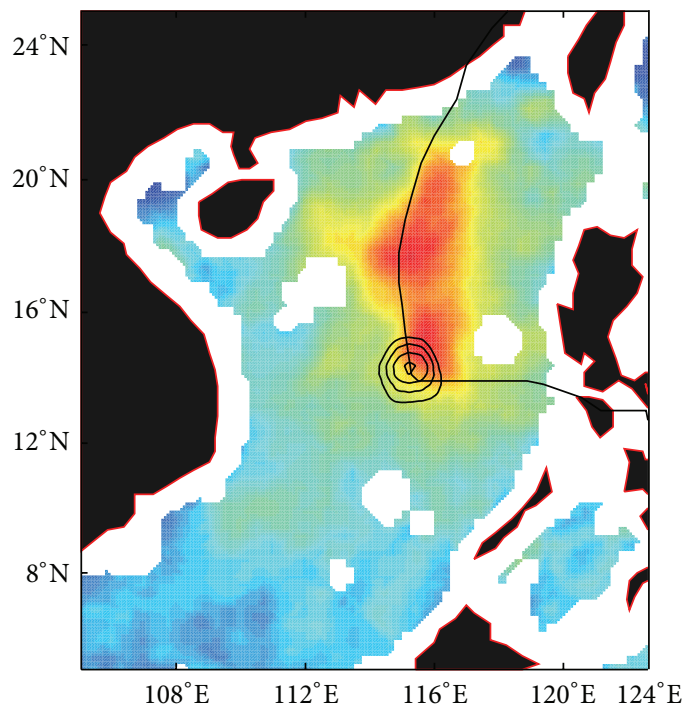

(e)

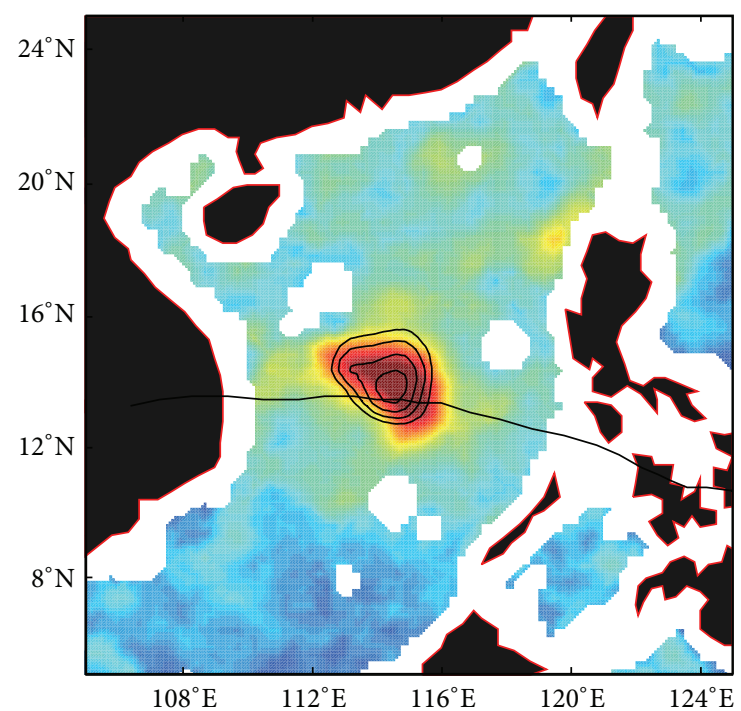

(b)

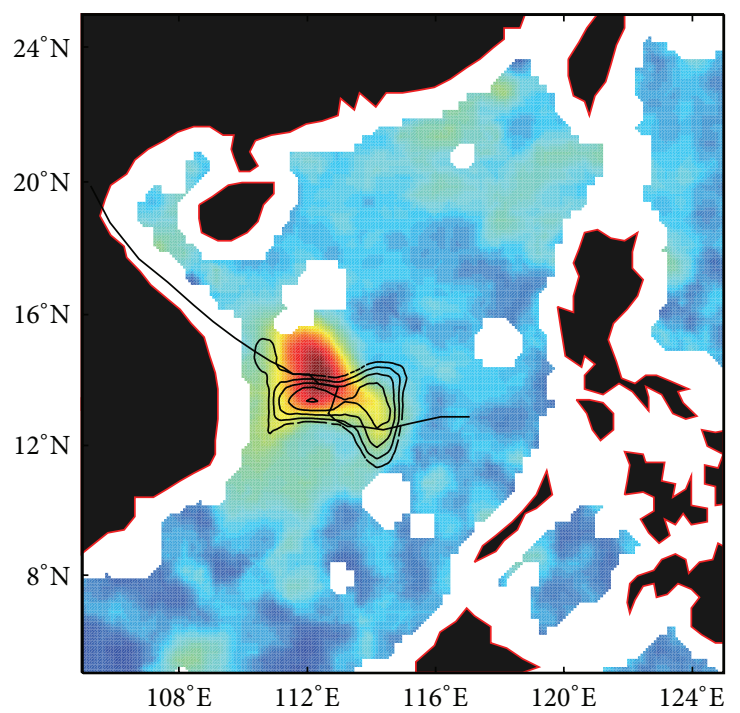

(d)

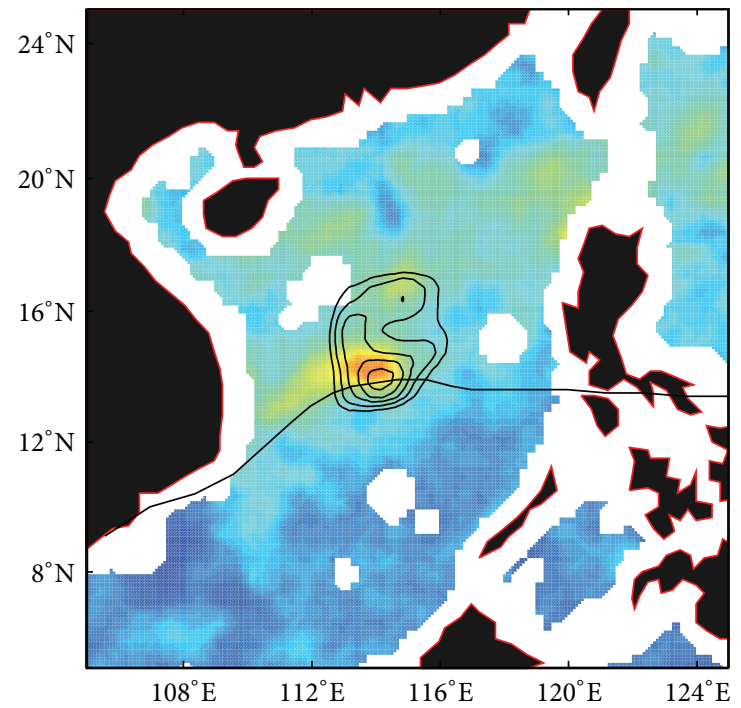

(f)

FIgUre 11: Continued. 


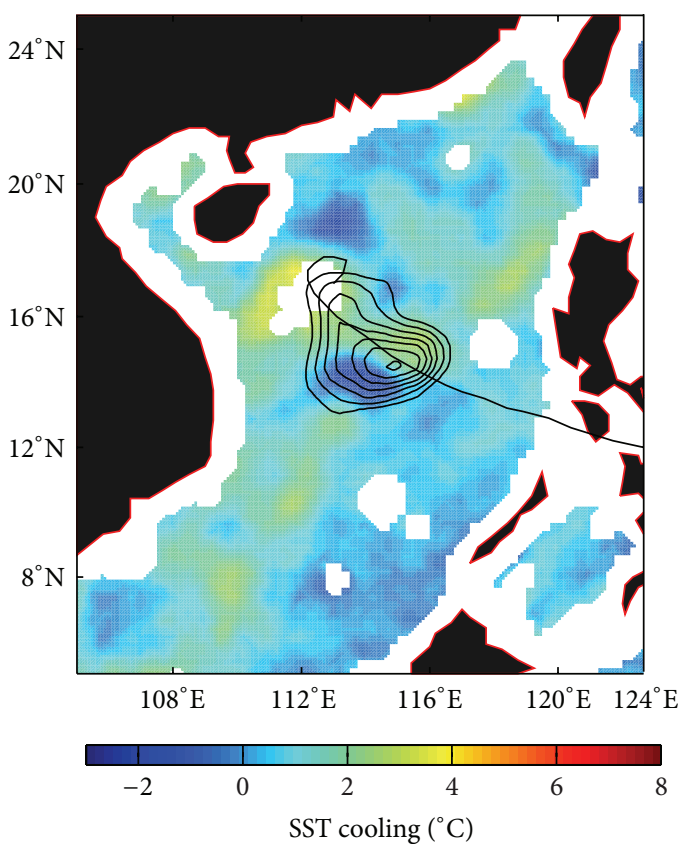

(g)

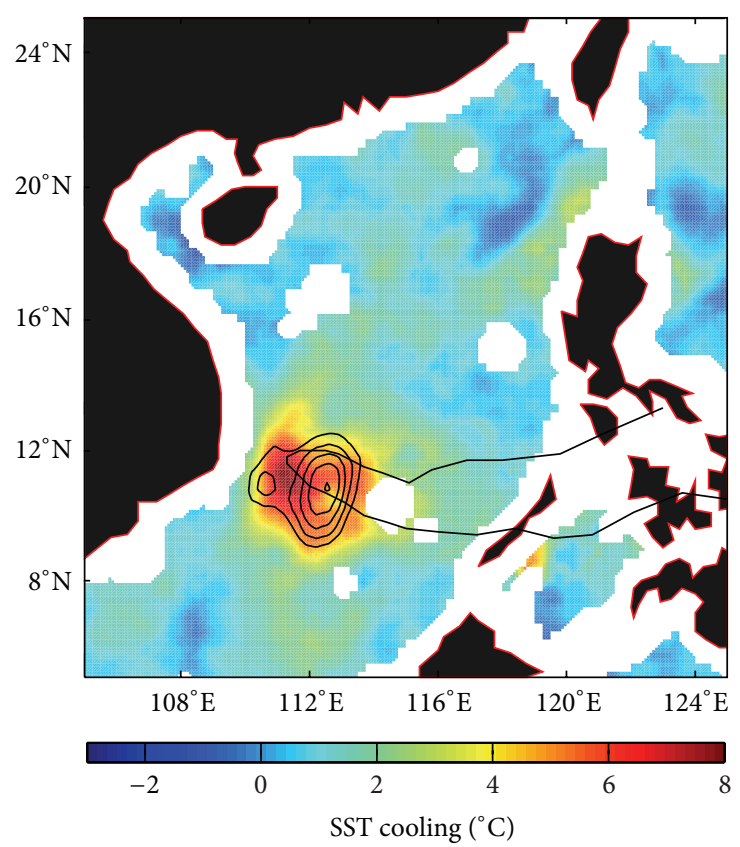

(h)

FIGURE 11: The SST cooling under the influence of typhoons in the CCE area. The thick black solid lines in figures are typhoon tracks. The closed contours are the CCEs influenced by typhoons. The colorbar is the temperature difference before storm and after storm; the exact prestorm and poststorm day are from Table 3. (a) Typhoon Leo, (b) Lingling, (c) Nanmadol, (d) Kai-tak, (e) Chanchu, (f) Durian, (g) Utor, and (h) Hagibis. The date of the CCEs is on the day that typhoon passed the CCE.

the more changes in SST at the center of the CCE caused by typhoons, the larger changes in EAGPE of the CCE. However, SST is controlled by many factors, such as turbulent mixing, surface radiative forcing, and evaporation. The relationship between SST changes and EAGPE variations cannot be so easily addressed and this is why their relationship cannot be described by a simple formula in this analysis.

\section{Discussion}

It is noted that the chl-a average in CCE areas is averaged from all the chl-a pixel values in the CCE. Thus, the poststorm peak pixel values are always much larger than the average ones. For example, in Leo's case, average concentration was $0.7174 \mathrm{mg} / \mathrm{m}^{3}$, while there were about $8 \%$ pixel with values higher than $2 \mathrm{mg} / \mathrm{m}^{3}$.

The increase of chl-a is related to ocean conditions such as where preexisting CCE located, over the continent slope or deep sea regions, which may influence the horizontal and vertical distribution of chl-a in preexisting CCE regions. Moreover, local nutrients, water temperature, and ocean currents also impact the condition of phytoplankton bloom. Storm factors such as maximum wind speed and transit speed of storms are also influential. Leo and Chanchu occurred in spring, and the corresponding preexisting CCEs were over the regional continent slope of the northern SCS and in the center of the SCS, respectively. The prestorm chl-a concentration was lower in the center of the SCS than that over continent slope. Though the transit speed of Chanchu was lower than Leo's, the poststorm chl-a for Leo was higher than that for Chanchu. It is proposed that the sea water over continent slope of the northern SCS has more nutrient than that in the center of the SCS. Here, at the end of April, the monsoon with southeastern direction cannot induce the upwelling and did not influence the chl-a concentration of preexisting CCE for Leo. The preexisting CCE for Chanchu is in the center of SCS and far from the coast. The monsoon also did not influence the chl-a in the CCE; therefore the chl-a in the CCE was dominantly influenced by both the preexisting CCE and Chanchu's effect.

The other typhoons occurred in autumn and winter; the prestorm chl-a in preexisting CCEs was higher than those of Leo and Chanchu due to different seasons. Therein, the prestorm chl-a of preexisting CCE for Kai-tak was somewhat higher than others, which may be explained by upwelling induced by monsoon (see Figures 2 and 8(b)). For Nanmadol, based on Figures 2 and 8(a), it is found that the highest chl-a concentration induced by monsoon was out of the region in a preexisting CCE, and the preexisting CCE for Nanmadol was in the deep sea region $(>3000 \mathrm{~m})$; therefore, monsoon effect can be ignored. However, in December, the southwestward wind may bring a small quality of chl-a from the Luzon Strait to the preexisting CCE; thus, the prestorm chl-a of the preexisting CCE for Nanmadol was also somewhat higher than others. In posttyphoon chl-a distribution, the chl-a pixel values had a larger gradient in the CCE area, which indicates that 
the chl-a response was not uniform. There are three types of posttyphoon chl-a distributions in CCE areas.

(1) The enhanced chl-a is around the maximum negative SSHA. For the cases of Leo, Lingling, and Hagibis, the higher chl-a values concentrated in the closed contours around the maximum negative SSHA, and there was not an obvious right-biased feature.

(2) The enhanced chl-a concentration in CCE presents a right-biased feature such as in the cases of Chanchu, Durian, and Utor, where the chl-a increase occurs mainly on the right of each typhoon's tracks in the CCEs.

(3) The enhanced chl-a concentration is not in the center of the CCE. For the cases of Kai-tak and Nanmadol, the distribution of higher chl-a had deviated from closed contours in the center. For Nanmadol, its track was relatively far from the CCE where the pattern of chl-a bloom was outside of the CCE. That is, higher chl-a had deviated from the CCE center and was on the right side of the track. It is noted that the region of chl-a bloom with highest concentration was near the Philippines coast, where rich nutrients from the land are washed down by rain. Based on Figures 2, 8(a), 9(a), and 11(c), it is clear that Nanmadol induced the lower SST in the CCE region; thus, the posttyphoon chl-a in the CCE was mainly induced by typhoon, though a small part of phytoplankton may be from the Luzon Strait to the CCE by horizontal advection. It is also found that between the CCE and the Philippines coast there was significantly lower chl-a, which suggests that there was no upwelling in the coast located in the eastern CCE. For slow transit typhoon Kai-tak, which overlaid a large CCE covering poor and rich nutrients regions of sea, the concentration of chl-a was highest in the region toward the coast rather than in the center of the CCE. It is noted that the chl-a concentration was not continuous and lower between the Vietnam coast and the CCE, which indicates that monsoon effects can be ignored. Based on Figures 2, 8(b), 9(b), and 11(d), the lowest SST may be induced by typhoon entrainment and mixing while the enhanced CCE interacted with the topography. Thereby, the distribution of lowest SST may be influenced by topography and was not in the center of CCE, so did the distribution of chl-a.

When typhoon overlays the region where no CCE persists, the potential upwelling velocity caused by typhoon wind stress is expressed by using the Ekman pumping velocity (EPV) formula [41],

$$
\mathrm{EPV}=\operatorname{curl}\left(\frac{\vec{\tau}}{\rho f}\right),
$$

where $\rho$ is the density of sea water, $f$ is the Coriolis parameter, and $\vec{\tau}$ is the wind stress. The EPV is a decisive factor for cooling down the sea surface temperature and transforming the nutrient water from deep layer to euphotic layer. However,
Sun et al. [40] argued that the forcing time of typhoons must exceed geostrophic adjustment time if upwelling velocity reaches EPV in (7); otherwise, the upwelling will be less. So when the forcing time reaches geostrophic adjustment time, the upwelling velocity reaches its maximum.

When a typhoon acts on the region with CCE, upwelling velocity should include two parts:

$$
\mathrm{EPV}_{2}=\mathrm{EPV}^{\prime}+\mathrm{EPV}_{1}
$$

where $\mathrm{EPV}_{1}$ is upwelling velocity attributed to preexisting cyclonic eddy and $\mathrm{EPV}^{\prime}$ is upwelling velocity attributed to typhoon without preexisting CCE.

When a typhoon acts on the region with CCE, the vertical mixing induced by turbulence dominates cooling (75\%$90 \%$ ) in the mixed layer [2], and upwelling only enhances entrainment under slowing transit typhoons and further lifts up the isotherms of CCE [18]. Both vertical mixing and upwelling all cool down the SST, indicating transformation of the nutrients from deeper to shallower.

Since upwelling can lift up the isotherms of CCE, which changes the depth of thermocline, $\mathrm{EPV}_{2}$ should be a key parameter to transform the nutrient saltiness from the deeper layer (deeper than mixed layer) to the depth where phytoplankton blooms. Thus the amount of transporting nutrient saltiness can be estimated by this $\mathrm{EPV}_{2}$. Hence, in (8), supposing $\mathrm{EPV}_{1}$ is a constant, $\mathrm{EPV}^{\prime}$ is still a dominant factor to enhance the chl-a in a CCE region when the typhoon overlays the CCE. In the observation, the largest $\mathrm{EPV}^{\prime}$ was for Hagibis, which corresponds to the largest chl-a increase: $1.4338 \mathrm{mg} / \mathrm{m}^{3}$ in a CCE located in the poor nutrient region. The chl-a increases induced by other typhoons were much lower than the value corresponding to Hagibis, because their forcing time was less than geostrophic adjustment time.

In eight typhoon cases, those typhoons with very slow moving velocity, such as typhoon Leo, Kai-tak, and Hagibis, above their corresponding CCEs had much higher poststorm chl-a concentration than that when typhoons had no CCEs in their way (see Figures 4, 7, 9, and 10). Thus, for the slow moving typhoon, the preexisting CCE plays an important role in enhancing the chl-a concentration. Also, the prestorm chl-a concentration in a CCE influenced by monsoon can be ignored for typhoon Leo, Kai-tak, and Hagibis. For typhoons with transit speeds greater than $3 \mathrm{~m} / \mathrm{s}$ like Nanmadol and Utor, the ratio of poststorm chl-a/prestorm chl-a was less than 3.9. It reveals that the chl-a contribution from preexisting CCE cannot be ignored. In short, preexisting CCE conditions are important for nutrient transport from deep to upper layers.

The CCEs studied here were generated locally, and in the observation, they did not entangle the coastal phytoplankton in their center. All in all, for the poststorm chl-a concentration, though many factors may affect an ocean response to storm, the preexisting CCE and typhoon transit speed are still the main dynamic factors to influence chl-a concentration. This result is in agreement with the previous study [18].

For chl-a concentration, the data we employed are from NASA (level-3); the arithmetic and solution are accredited. The preexisting CCEs are at least $100 \mathrm{~km}$ far from the Vietnam 
and Philippine coasts and more than $300 \mathrm{~km}$ far from rivers. Therefore, the influence to our observation results by the suspended sediments and CDOM (colored or chromophoric dissolved organic matter) can also be ignored.

It is needed to point out that, except for kinetic energy and gravitational potential energy, typhoons input more energy into the surface waves (1.62 TW) [42], which may enhance vertical mixing. The amount of energy increasement of CCEs just partly demonstrates the energy that typhoons input into the ocean, which reflects the upper ocean responding to typhoons in one way. In addition to the influence of typhoons, other factors may induce the change of CCEs, such as topography and background current. According to the purposes of this study, we only concentrated on the influence of typhoons. The inertial waves induced by typhoon also can enhance the vertical mixing, which can cover the depth from mixed layer to thermocline; however, most energy of inertial waves is out of the CCE center $[1,7,43]$. In the study, the effect on CCEs by inertial waves is ignored.

From the observations, the CCEs are always intensified after typhoons, and CCEs' centers tend to move toward typhoon tracks. When typhoon influences the overlaid CCE, the preexisting CCE is transferred or merges with the cyclonic eddy that triggered by the impending typhoon. To avoid this complex process, we calculated the EKE and EAGPE from the satellite data 4 days after a typhoon passed by a CCE. At the same time, because phytoplankton blooms are 3 5 days after typhoons pass, it is more reasonable to examine the CCEs' area by SSHA data 4 days after typhoon, to describe the relation between chl-a and energy of the CCE.

The estimated value of EKE and EAGPE for CCE are based on SSHA and WOA05. Unfortunately, some idealized assumptions in definition of eddy boundaries and eddy vertical structure and the practical difficulty of observing the CCEs' change during the typhoon occurrences both limit the accuracy of eddy energy estimations. However, in order to not only qualitatively discuss the changes of CCEs' shapes influenced by the typhoons but also explore the energy flow between the atmospheric forcing and the oceanic response, a method was used to calculate the baroclinic energy of preexisting CCE response to typhoons and derive significant results. Errors exist and are hard to estimate, but we believe our results are not strongly affected by them. Moreover, the results are in agreement with the numerical results of Zheng el al. [17] and satellite data-based evaluation of Sun et al. [44] (please note that Sun et al's study focused on the typhoons in the Western North Pacific Ocean).

\section{Conclusions}

In this study, with the absence of in situ data, we proposed an effective method to estimate CCE areas with the influence of typhoons, examining the EKE and EAGPE changes and their ecological factors. We investigated chl-a change in CCE areas and described the CCEs' change by EKE and EAGPE using a reduced gravity model before and after eight typhoon cases in SCS. The changes of preexisting baroclinic eddies induced by typhoons are presented by the changes of EKE and EAGPE, and the increments of EKE are generally less than these of EAGPE. The maximum ratio of poststorm EKE/ prestorm EKE reaches 5.0 times, while the maximum ratio of poststorm EAGPE/prestorm EAGPE reaches about 8.9 times; thereby, typhoons significantly change the EAGPE of preexisting CCEs, though most of CCEs' EKE and EAGPE increase simultaneously by the influence of typhoons.

In eight typhoon cases, for typhoon with transit speeds greater than $3 \mathrm{~m} / \mathrm{s}$ (Nanmadol, Utor), the preexisting CCE plays an important role in enhancing the chl-a, and it is not ignored comparing to poststorm CCE. The chl-a concentration in preexisting CCE is $25 \%$ to $45 \%$ of those of poststorm CCE, while for typhoon with transit speeds less than $3 \mathrm{~m} / \mathrm{s}$, the chl-a concentration in preexisting CCE is about $8 \%$ to $25 \%$ of those of poststorm CCE. In the CCE area, when the ratio of posttyphoon EAGPE to pretyphoon EAGPE is large, the corresponding ratio of posttyphoon chl-a to pretyphoon chl-a is large too. In addition, we quantitatively calculate the EAGPE (EKE) enhanced from $1.8 \times 10^{15}(0.2 \times$ $\left.10^{15}\right)$ to $5.1 \times 10^{15}\left(2.9 \times 10^{15}\right)$ J by typhoon with transit speeds less than $3 \mathrm{~m} / \mathrm{s}$ and from $0.4 \times 10^{15}\left(-0.17 \times 10^{15}\right)$ to $3.7 \times$ $10^{15}\left(1 \times 10^{15}\right)$ J by Typhoon with transit speeds greater than $3 \mathrm{~m} / \mathrm{s}$. The enhanced EAGPE (EKE) of CCEs offers evidence for further study on enhanced mixing and deep sea currents by poststorm CCE.

\section{Conflict of Interests}

The authors declare that there is no conflict of interests regarding the publication of this paper.

\section{Acknowledgments}

This study is supported by Grant XDA11010202, Projects U1033002, 41376022, 41276021, and 41306016 of the Natural Science Foundation of China, and Project 2013CB430303 of the National Basic Research Program. Comments from two referees are highly appreciated.

\section{References}

[1] A. E. Gill, "On the behavior of internal waves in the wake of storms," Journal of Physical Oceanography, vol. 14, no. 7, pp. 1129-1151, 1984.

[2] S. D. Jacob, L. K. Shay, A. J. Mariano, and P. G. Black, "The 3D oceanic mixed layer response to Hurricane Gilbert," Journal of Physical Oceanography, vol. 30, no. 6, pp. 1407-1429, 2000.

[3] T. B. Sanford, P. G. Black, J. R. Haustein, J. W. Feeney, G. Z. Forristall, and J. F. Price, "Ocean response to a hurricane: I. Observations," Journal of Physical Oceanography, vol. 17, no. 11, pp. 2065-2083, 1987.

[4] T. Dickey, D. Frye, J. McNeil et al., "Upper-ocean temperature response to hurricane Felix as measured by the Bermuda testbed mooring," Monthly Weather Review, vol. 126, no. 5, pp. 11951201, 1998.

[5] T. D. Dickey and J. J. Simpson, "The sensitivity of upper ocean structure to time varying wind direction," Geophysical Research Letters, vol. 10, no. 2, pp. 133-136, 1983.

[6] J. F. Price, "Upper ocean response to a hurricane," Journal of Physical Oceanography, vol. 11, no. 2, pp. 153-175, 1981. 
[7] X. P. Jiang, Z. Zhong, and J. Jiang, "Upper ocean response of the South China Sea to Typhoon Krovanh (2003)," Dynamics of Atmospheres and Oceans, vol. 47, no. 1-3, pp. 165-175, 2009.

[8] M. J. Furnas, "Cyclonic disturbance and a phytoplankton bloom in a tropical shelf ecosystem," in Red Tides: Biology, Environmental Science and Toxicology: Proceedings of the 1st International Symposium on Red Tides held November 10-14, 1987, T. Okaichi, D. M. Anderson, and T. Nemoto, Eds., pp. 273-276, Elsevier Science Publishing, Takamatsu, Japan, 1989.

[9] B. Delesalle, M. Pichon, M. Frankignoulle, and J. P. Gattuso, "Effects of a cyclone on coral reef phytoplankton biomass, primary production and composition (Moorea Island, French Polynesia)," Journal of Plankton Research, vol. 15, no. 12, pp. 1413-1423, 1993.

[10] J. Chang, C.-C. Chung, and G.-C. Gong, "Influences of cyclones on chlorophyll a concentration and Synechococcus abundance in a subtropical western Pacific coastal ecosystem," Marine Ecology Progress Series, vol. 140, no. 1-3, pp. 199-205, 1996.

[11] S. M. Babin, J. A. Carton, T. D. Dickey, and J. D. Wiggert, "Satellite evidence of hurricane-induced 9 phytoplankton blooms in an oceanic desert," Journal of Geophysical Research, vol. 109, Article ID C03043, 2004.

[12] M. N. Hanshaw, M. S. Lozier, and J. B. Palter, "Integrated impact of tropical cyclones on sea surface chlorophyll in the North Atlantic," Geophysical Research Letters, vol. 35, no. 1, Article ID L01601, 2008.

[13] N. D. Walker, R. R. Leben, and S. Balasubramanian, "Hurricaneforced upwelling and chlorophyll a enhancement within coldcore cyclones in the Gulf of Mexico," Geophysical Research Letters, vol. 32, no. 18, Article ID L18610, pp. 1-5, 2005.

[14] I. Lin, W. T. Liu, C.-C. Wu et al., "New evidence for enhanced ocean primary production triggered by tropical cyclone," Geophysical Research Letters, vol. 30, no. 13, article 1718, 2003.

[15] S. Shang, L. Li, F. Q. Sun et al., "Changes of temperature and bio-optical properties in the South China Sea in response to Typhoon Lingling, 2001," Geophysical Research Letters, vol. 35, no. 10, Article ID L10602, 2008.

[16] Y. Chen and D. Tang, "Eddy-feature phytoplankton bloom induced by a tropical cyclone in the South China Sea," International Journal of Remote Sensing, vol. 33, no. 23, pp. 7444-7457, 2012.

[17] Z.-W. Zheng, C.-R. Ho, and N.-J. Kuo, "Importance of preexisting oceanic conditions to upper ocean response induced by Super Typhoon Hai-Tang," Geophysical Research Letters, vol. 35, no. 20, Article ID L20603, 2008.

[18] X. M. Liu, M. H. Wang, and W. Shi, "A study of a Hurricane Katrina-induced phytoplankton bloom using satellite observations and model simulations," Journal of Geophysical Research C: Oceans, vol. 114, no. 3, Article ID C03023, 2009.

[19] P. G. Falkowski, D. Ziemann, Z. Kolber, and P. K. Bienfang, "Role of eddy pumping in enhancing primary production in the ocean," Nature, vol. 352, no. 6330, pp. 55-58, 1991.

[20] E. N. Sweeney, D. J. McGillicuddy Jr., and K. O. Buesseler, "Biogeochemical impacts due to mesoscale eddy activity in the Sargasso Sea as measured at the Bermuda Atlantic Time-series Study (BATS)," Deep-Sea Research Part II: Topical Studies in Oceanography, vol. 50, no. 22-26, pp. 3017-3039, 2003.

[21] F. Nencioli, V. S. Kuwahara, T. D. Dickey, Y. M. Rii, and R. R. Bidigare, "Physical dynamics and biological implications of a mesoscale eddy in the lee of Hawai' i: cyclone Opal observations during E-Flux III," Deep-Sea Research Part II: Topical Studies in Oceanography, vol. 55, no. 10-13, pp. 1252-1274, 2008.
[22] Z. W. Zheng, C. R. Ho, Q. Zheng, Y. T. Lo, N. J. Kuo, and G. Gopalakrishnan, "Effects of preexisting cyclonic eddies on upper ocean responses to Category 5 typhoons in the western North Pacific," Journal of Geophysical Research C: Oceans, vol. 115, no. 9, Article ID C09013, 2010.

[23] T. G. Prasad and P. J. Hogan, "Upper-ocean response to Hurricane Ivan in a $1 / 25^{\circ}$ nested Gulf of Mexico HYCOM," Journal of Geophysical Research C: Oceans, vol. 112, no. 4, Article ID C04013, 2007.

[24] C. Eden and H. Dietze, "Effects of mesoscale eddy/wind interactions on biological new production and eddy kinetic energy," Journal of Geophysical Research C: Oceans, vol. 114, no. 5, Article ID C05023, 2009.

[25] F. Jia, L. Wu, and B. Qiu, "Seasonal modulation of eddy kinetic energy and its formation mechanism in the southeast Indian Ocean," Journal of Physical Oceanography, vol. 41, no. 4, pp. 657665, 2011.

[26] S. M. Chen and B. Qiu, "Mesoscale eddies northeast of the Hawaiian archipelago from satellite altimeter observations," Journal of Geophysical Research C: Oceans, vol.115, no. 3, Article ID C03016, 2010.

[27] C. Xu, X.-D. Shang, and R. X. Huang, "Estimate of eddy energy generation/dissipation rate in the world ocean from altimetry data," Ocean Dynamics, vol. 61, no. 4, pp. 525-541, 2011.

[28] G. Wang, J. Su, Y. Ding, and D. Chen, “Tropical cyclone genesis over the south China sea," Journal of Marine Systems, vol. 68, no. 3-4, pp. 318-326, 2007.

[29] G. Wang, J. Su, and C. Chu, "Mesoscale eddies in the South China Sea observed with altimeter data," Geophysical Research Letter, vol. 30, article 2121, 2003.

[30] L. Y. Yuang, Distribution and characteristics of nutrients in the Northern South China Sea [M.S. thesis], Xiamen University, 2005.

[31] S.-P. Xie, Q. Xie, D. Wang, and W. T. Liu, "Summer upwelling in the South China Sea and its role in regional climate variations," Journal of Geophysical Research C: Oceans, vol. 108, no. C8, article 3261, 2003.

[32] J. E. O’Reilly, S. Maritorena, B. G. Mitchell et al., "Ocean color chlorophyll algorithms for SeaWiFS," Journal of Geophysical Research C: Oceans, vol. 103, no. 11, pp. 937-953, 1998.

[33] A. Davis and X.-H. Yan, "Hurricane forcing on chlorophyll-a concentration off the northeast coast of the U.S.," Geophysical Research Letters, vol. 31, no. 17, Article ID L17304, 2004.

[34] D. Roemmich and J. Gilson, "Eddy transport of heat and thermocline waters in the North Pacific: a key to interannual/ decadal climate variability?" Journal of Physical Oceanography, vol. 31, no. 3, pp. 675-687, 2001.

[35] G. Forget and C. Wunsch, "Estimated global hydrographic variability," Journal of Physical Oceanography, vol. 37, no. 8, pp. 1997-2008, 2007.

[36] J. Y. Pan and Y. Sun, "Estimate of ocean mixed layer deepening after a typhoon passage over the south china sea by using satellite data," Journal of Physical Oceanography, vol. 43, no. 3, pp. 498-506, 2013.

[37] C.-Y. Lin, C.-R. Ho, Z.-W. Zheng, and N.-J. Kuo, "Validation and variation of upper layer thickness in South China sea from satellite altimeter data," Sensors, vol. 8, no. 6, pp. 3802-3818, 2008.

[38] R. X. Huang, Ocean Circulation, Wind-Driven and Thermohaline Processes, Cambridge University Press, Cambridge, UK, 2010. 
[39] C. Chen, P. Shi, and Q. Mao, "Satellite remotely-sensed analysis of distribution characters of chlorophyll concentration in South China Sea," Journal of Tropical Oceanography, vol. 20, pp. 66-70, 2001.

[40] L. Sun, Y.-J. Yang, T. Xian, Z.-M. Lu, and Y.-F. Fu, "Strong enhancement of chlorophyll a concentration by a weak typhoon," Marine Ecology Progress Series, vol. 404, pp. 39-50, 2010.

[41] J. F. Price, T. B. Sanford, and G. Z. Forristall, "Forced stage response to a moving hurricane," Journal of Physical Oceanography, vol. 24, no. 2, pp. 233-260, 1994.

[42] L. L. Liu, W. Wang, and R. X. Huang, "The mechanical energy input to the ocean induced by tropical cyclones," Journal of Physical Oceanography, vol. 38, no. 6, pp. 1253-1266, 2008.

[43] J. F. Price, "Internal wave wake of a moving storm. Part I: scales, energy budget and observations," Journal of Physical Oceanography, vol. 13, no. 6, pp. 949-965, 1983.

[44] L. Sun, Y.-X. Li, Y.-J. Yang et al., "Effects of super typhoons on cyclonic ocean eddies in the western North Pacific: a satellite data-based evaluation between 2000 and 2008," Journal of Geophysical Research, vol. 119, no. 9, pp. 5585-5598, 2014. 

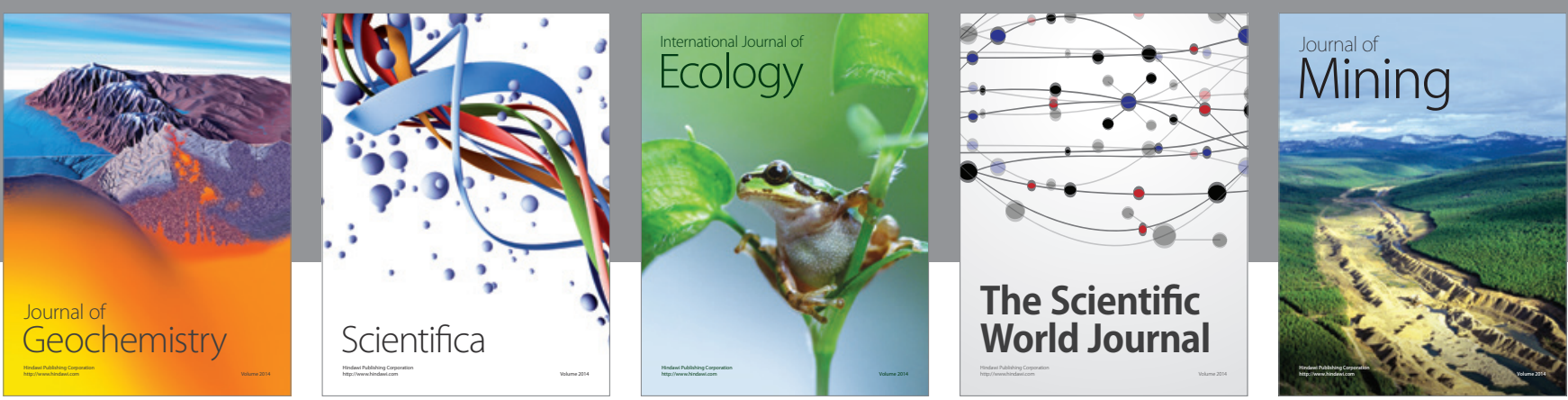

The Scientific World Journal
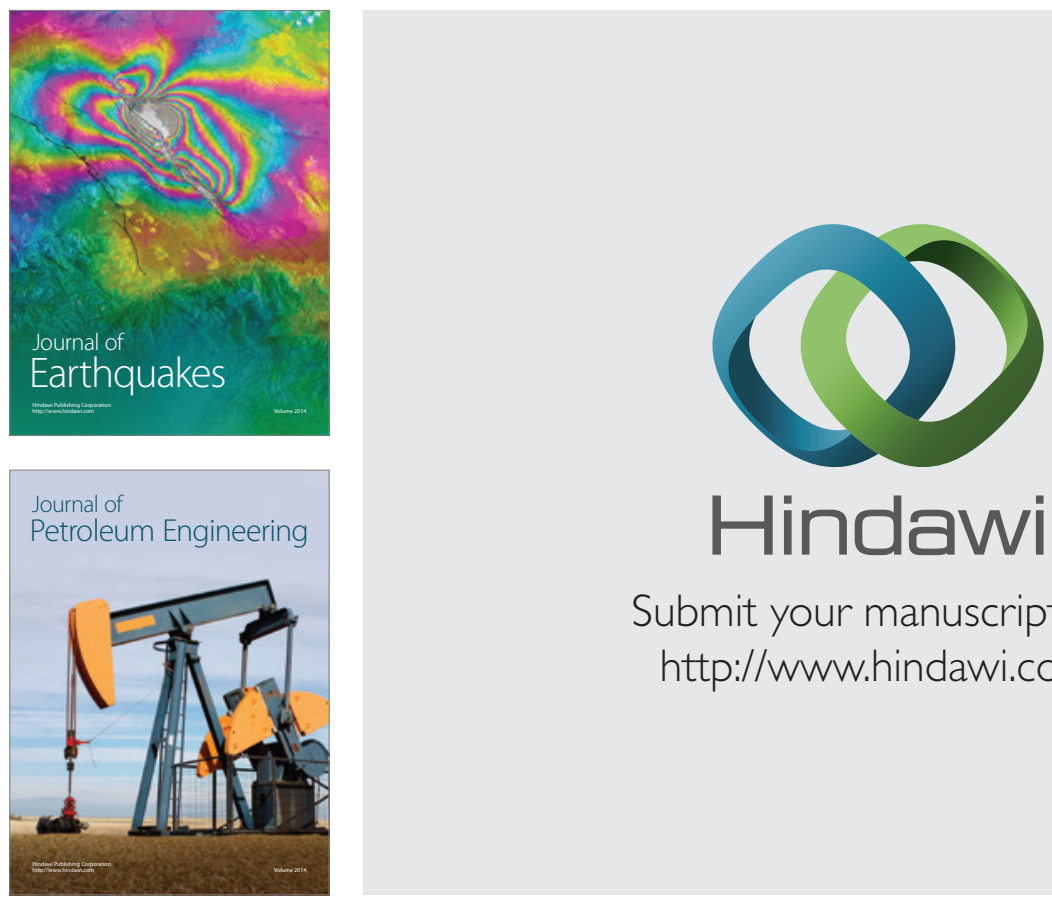

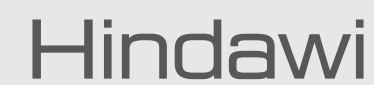

Submit your manuscripts at

http://www.hindawi.com
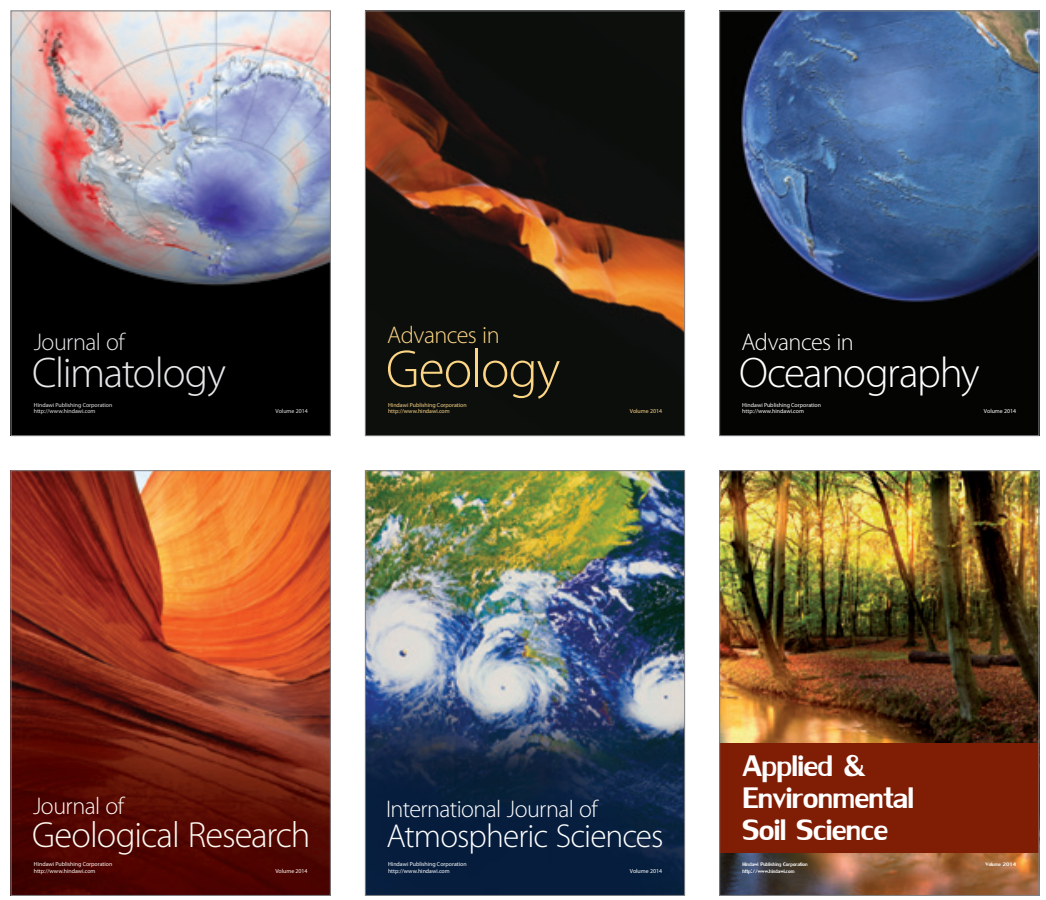
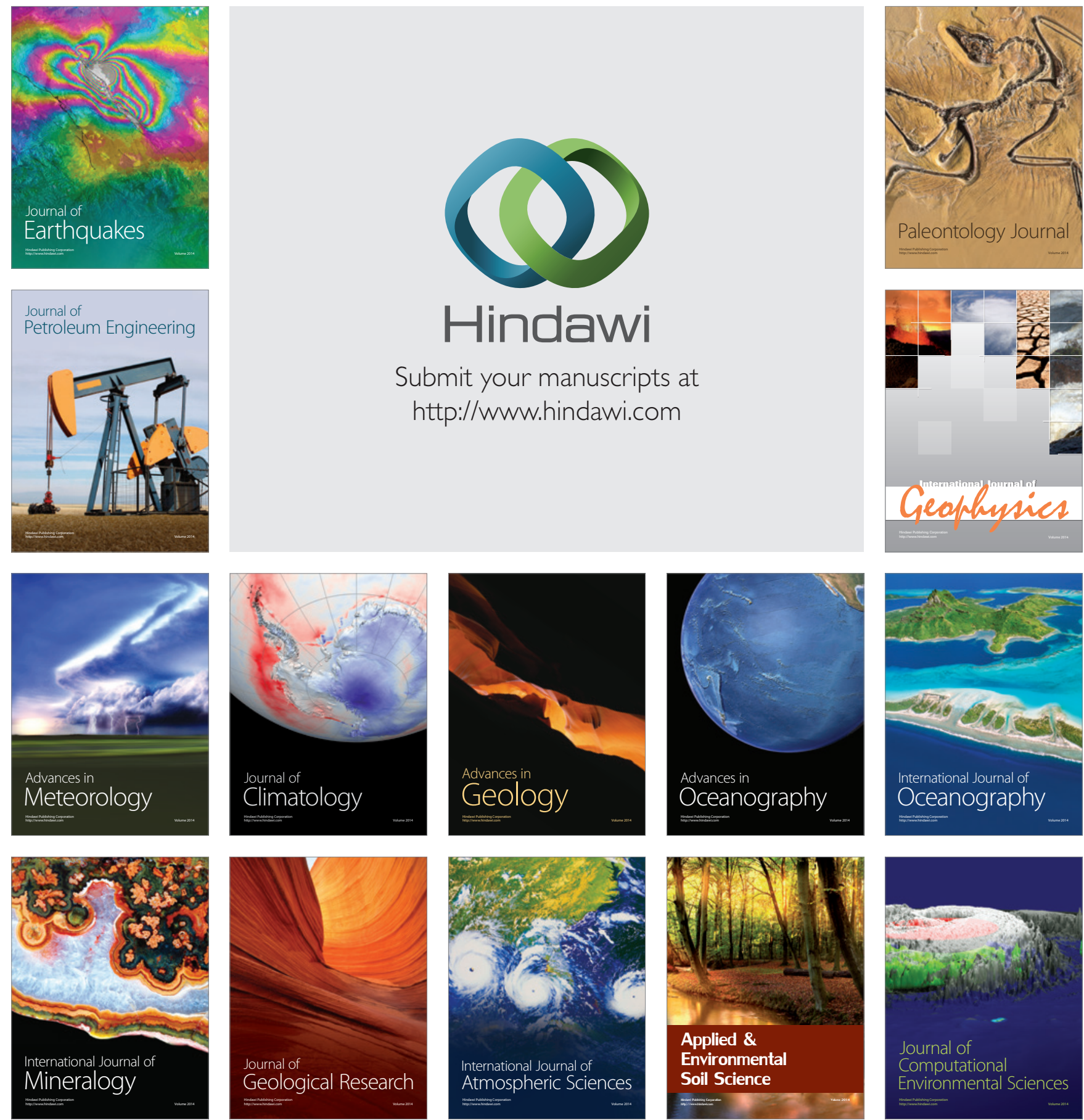